\title{
ANDRO: An Argo-Based Deep Displacement Dataset
}

\author{
Michel OlLitrault \\ Laboratoire de Physique des Océans, CNRS/IFREMER/IRD/UBO, IFREMER/Centre de Brest, Plouzané, France \\ JEAN-PHILIPPE RANNOU \\ ALTRAN Ouest, Technopole Brest Iroise, Site du Vernis, Brest, France
}

(Manuscript received 20 April 2012, in final form 27 August 2012)

\begin{abstract}
During the first decade of the twenty-first century, more than 6000 Argo floats have been launched over the World Ocean, gathering temperature and salinity data from the upper $2000 \mathrm{~m}$, at a 10-day or so sampling period. Meanwhile their deep displacements can be used to map the ocean circulation at their drifting depth (mostly around $1000 \mathrm{~m}$ ). A comprehensive processing of the whole Argo dataset collected prior to 1 January 2010 has been performed to produce a world-wide dataset of deep displacements. This numerical atlas, named ANDRO, after a traditional dance of Brittany meaning a swirl, comprises some 600000 deep displacements. These displacements, based on Argo or GPS surface locations only, have been fully checked and corrected for possible errors found in the public Argo data files (due to incorrect decoding or instrumental failure). Park pressures measured by the floats while drifting at depth are preserved in ANDRO (less than $2 \%$ of the park pressures are unknown): $63 \%$ of the float displacements are in the layer $(900,1100)$ dbar with a good (more or less uniform) degree of coverage of all the oceans, except around Antarctica (south of $60^{\circ} \mathrm{S}$ ). Two deeper layers- $(1400,1600)$ and $(1900,2100)$ dbar-are also sampled $(11 \%$ and $8 \%$ of the float displacements, respectively) but with poorer geographical coverage. Grounded cycles (i.e., if the float hits the sea bottom) are excluded. ANDRO is available online as an ASCII file.
\end{abstract}

\section{Introduction}

\section{a. Some history}

Subsurface ocean currents can be measured directly with neutrally buoyant floats drifting at constant depth or at constant density. The first floats developed were tracked acoustically, either from a ship (Swallow 1955) or with an array of listening stations (Rossby and Webb 1970). It was soon recognized, however, that it would be cheaper and more convenient to use moored acoustic sources instead, and lighter listening floats, so that a greater number could be launched to better sample a given oceanic area. The first such float developed by Rossby et al. (1986), called RAFOS [i.e., sound fixing and ranging (SOFAR) reversed], surfaces after its deep journey (of the order of $1 \mathrm{yr}$ ) and then transmits its data to the Argos system, so that it can be tracked afterward.

Corresponding author address: M. Ollitrault, Laboratoire de Physique des Océans, CNRS/IFREMER/IRD/UBO, IFREMER/ Centre de Brest, BP 70, 29280 Plouzané, France.

E-mail: michel.ollitrault@ifremer.fr
Meanwhile, and just before the World Ocean Circulation Experiment (WOCE), a new design appeared: the autonomous Lagrangian circulation explorer (ALACE) float (Davis et al. 1992), which cycles periodically (e.g., every 3 weeks) between a prescribed depth and the surface, where it can be located by the Argos system. This float had no acoustic tracking. A few years later, the MARVOR (sea horse in the language of Brittany) float, which combines both the acoustic system of the RAFOS and the cycling capability of the ALACE, was developed in France (Ollitrault et al. 1994), also to be used in WOCE.

Acoustic floats sample mesoscale motions well, since their subsurface trajectories are triangulated once per day (generally) at the depth where they drift (whether they be isopycnal or isobaric), thus approximately tagging water particles. ALACEs have no acoustic tracking but can be deployed over the whole ocean (for practical reasons, an acoustic source array covers at most an ocean basin, not taking into consideration acoustic propagation problems). The position accuracy of acoustic floats (with a redundant source array) is of the order of a few 
kilometers. Argos surface fixes are generally obtained with an error of $1 \mathrm{~km}$ or less. An ALACE deep displacement is easily estimated as the distance between the last Argo fix (before diving) and the first Argos fix (after surfacing) of two consecutive cycles. This includes unknown errors due to the current shear between the drifting depth and the surface, and due to the delay between surfacing time and first Argos fix reception time (which may amount to several hours). The resulting position accuracy at drifting depth is consequently poorer, between 1 (at best) and $10 \mathrm{~km}$. Davis and Zenk (2001) give a general accounting of the induced error on velocity estimates (of the order of $1 \mathrm{~cm} \mathrm{~s}^{-1}$ with 10-day means).

\section{b. The Argo program}

Building on the knowledge accumulated from these floats, particularly during WOCE (during the last decade of the twentieth century), profiling floats, measuring pressure $p$, temperature $t$, and conductivity $C$ (or salinity $S$ ) while rising to the surface, were soon developed to be used within the framework of the Argo program (http:// www.argo.ucsd.edu/). Argo aims to measure the physical state of the global ocean (actually $t$ and $S$ in the upper $2000 \mathrm{~m}$ ) with an array of roughly 3000 floats (thus, approximately with a $300-\mathrm{km}$ resolution with floats launched uniformly) cycling every 10 days, and over a period of several years (possibly several decades). Float launchings began in 1999, but the number of 3000 floats working at sea at the same time was reached only in 2007 (by and large the uniform distribution of floats over the ocean was also attained). Generally floats have a life expectancy of only a few years and new ones have to be launched regularly to maintain an array of 3000 floats. Like ALACEs, Argo floats have no acoustic tracking. New models can now measure $\mathrm{O}_{2}$ with other climate-related parameters such as $\mathrm{pCO}_{2}$, for example, to be added soon.

A primary objective of Argo was to provide a quantitative description of the changing state of the upper ocean and the patterns of ocean climate variability from months to decades, including heat and freshwater storage and transport.

However, Argo float displacements at depth (roughly 9.5 days over a 10 -day total cycle time) also provide estimates of absolute velocity (averaged over the displacement times) all over the world with an approximate 10-day sampling period. Although such a velocity field is mainly restricted to one depth (around $1000 \mathrm{~m}$ ), if the estimates are accurate enough, it may solve the longstanding problem of the reference level (e.g., Wunsch 2008) for the first time. As far as the mean circulation is concerned, the accuracy of the velocity estimates is quite sufficient (e.g., Ollitrault et al. 2006) but may be questionable for studies focusing on monthly variations and in specific areas (e.g., the equatorial band). Actually, ALACE floats cycling every 3 weeks have already proven to be very efficient (e.g., Davis 2005) for mapping the velocity field around 1000-m depth, but Argo floats may go deeper $(2000 \mathrm{~m})$ and their cycling period is generally shorter (order of 10 days). An error estimate of these deep velocities is addressed in appendix A.

\section{c. The ANDRO atlas}

Yoshinari et al. (2006) first produced an atlas of velocity estimates (YoMaHa'05) by using the then-available Argo data. YoMaHa'07 (Lebedev et al. 2007) is a regularly updated version of this atlas (http://apdrc.soest.hawaii. edu/projects/Argo/data/trjctry/), which uses Argo data from the public Network Common Data Form (NetCDF) files found on the Global Data Assembly Center (GDAC) websites (http://www.coriolis.eu.org/ or http://www. usgodae.org/argo/). Generally, float displacements from YoMaHa'07 look quite realistic. But a few percent of the observations show high speeds or have drifting depths that are obviously inaccurate (e.g., some are found drifting over the continental shelf while their drifting depth is given as $1000 \mathrm{~m}$ ).

This convinced us to look more closely into the Argo data [and, when possible, to start anew from the very first Argos or Iridium raw data received at the different Data Assembly Centers (DAC)] to verify and (if necessary) correct the various parameters measured by the floats, which are used to estimate the float displacements (Ollitrault and Rannou 2010).

We present here what we have done so far with the whole Argo world data archive (until 1 January 2010 ${ }^{1}$ ) collected from the following DACs: the Atlantic Oceanographic and Meteorological Laboratory (AOML; United States), the Coriolis Project (France), the Japan Meteorological Agency (JMA), the Commonwealth Scientific and Industrial Research Organisation (CSIRO; Australia), the British Oceanographic Data Centre (BODC), the Marine Environmental Data Service (MEDS; Canada), the Indian National Centre for Ocean Information Services (INCOIS), the Korea Ocean Research and Development Institute (KORDI), the Korea Meteorological Administration (KMA), and the China Second Institute of Oceanography (CSIO).

First, the various float models used are presented: functioning, parking data measurement, and transmission. Then, the processing done on DAC NetCDF files and

\footnotetext{
${ }^{1}$ AOML Argo data for 2009, not processed at the time of this paper writing, are now included in ANDRO (29 November 2012 update).
} 


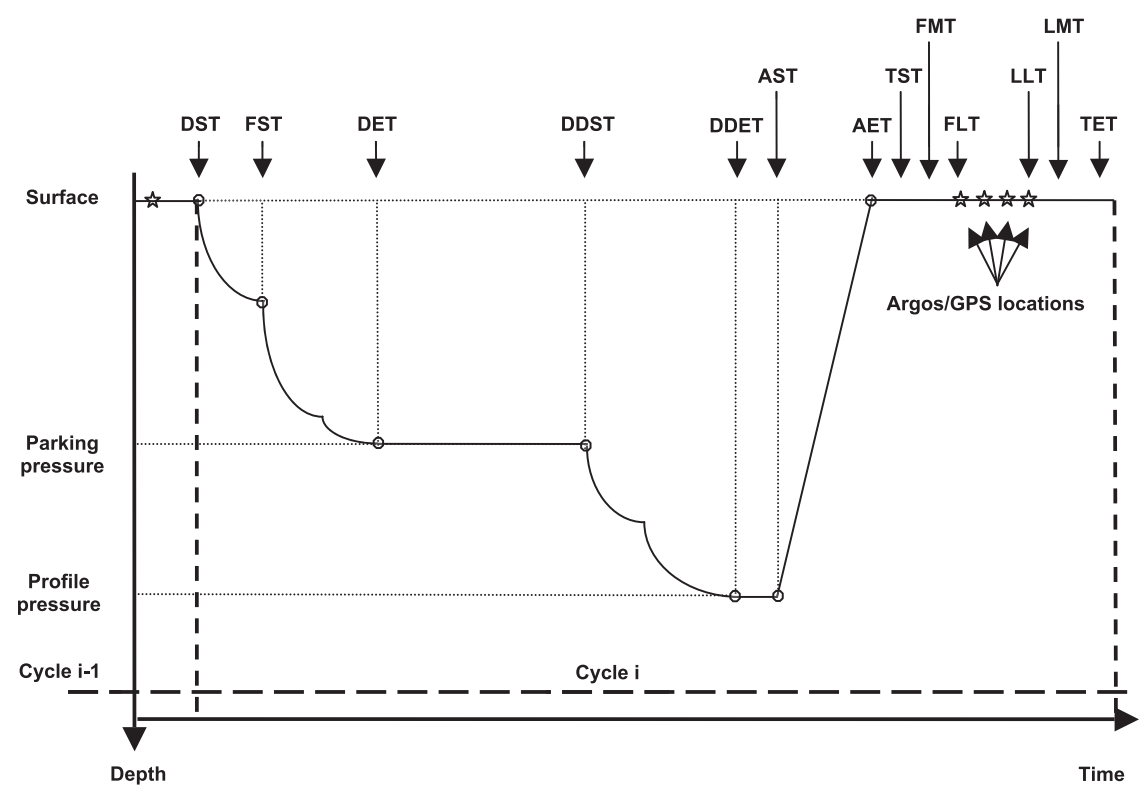

FIG. 1. Schematics of an Argo float cycle. An Argo cycle consists of five main phases: descent, park, deep descent, profile, and surface telemetry. Associated times are descent start time (DST), first stabilization time (FST), descent end time (DET), deep descent start time (DDST), deep descent end time (DDET), ascent start time (AST), ascent end time (AET), transmission start time (TST), and transmission end time (TET). First message time (FMT) and last message time (LMT) indicate the times of the first and last messages collected by the (Argos, Iridium, or OrbComm) satellite system while the float is emitting at the surface. First location time (FLT) and last location time (LLT) indicate the times of the first and last available surface float locations (from Argos or GPS).

Argos raw ASCII files is explained. In section 4, we present our deep displacement (velocity) atlas named ANDRO (for Argo New Displacements Rannou and Ollitrault, or because it is the name of a traditional dance of Brittany meaning a round or a swirl), resulting from our processing of Argo data.

Section 5 explains what could be done to improve the deep displacement estimates.

\section{The Argo floats}

There are three main models of Argo floats: the autonomous profiling explorer (APEX), SOLO, and PROVOR, contributing $61 \%, 26 \%$, and $11 \%$, respectively, to the total number of Argo floats used since 1999 (as of 1 January 2010). A few other float designs have been developed [e.g., NEMO in Germany, the (profiling) autonomous Lagrangian circulation explorer (PALACE) in the United States, or NINJA in Japan] but contribute only $2 \%$.

The different working phases that a float realizes during a given cycle are defined in Fig. 1 (the different times sequencing the different phases are explained in the caption).
Most of the Argo floats use the Argos satellite system for data transmission and surface positioning. Beginning in 2005, a few floats now use the Iridium (or OrbComm more recently) satellite system for data transmission and GPS for positioning. The main difference between the two systems is in their transmission strategy. Argos floats emit repeatedly all their messages during a sufficient time to enable a reliable acquisition by the few orbiting satellites (but there may remain transmission errors). Iridium floats first look for one satellite in the Iridium constellation, then send their messages over a short period of time (normally there are no transmission errors). Thus, Argo floats using Argos need to stay almost half a day at the surface to transmit (low data amount and longer waiting time for a satellite), while Argo floats using Iridium stay at the surface less than half an hour (with a much greater data amount transmitted).

Because no decoding is to be done on Iridium messages (which can contain all desired data and time information), almost all our work was concerned with a proper decoding of the Argos messages. That is why the following only presents the details of the different Argo float message structures. 


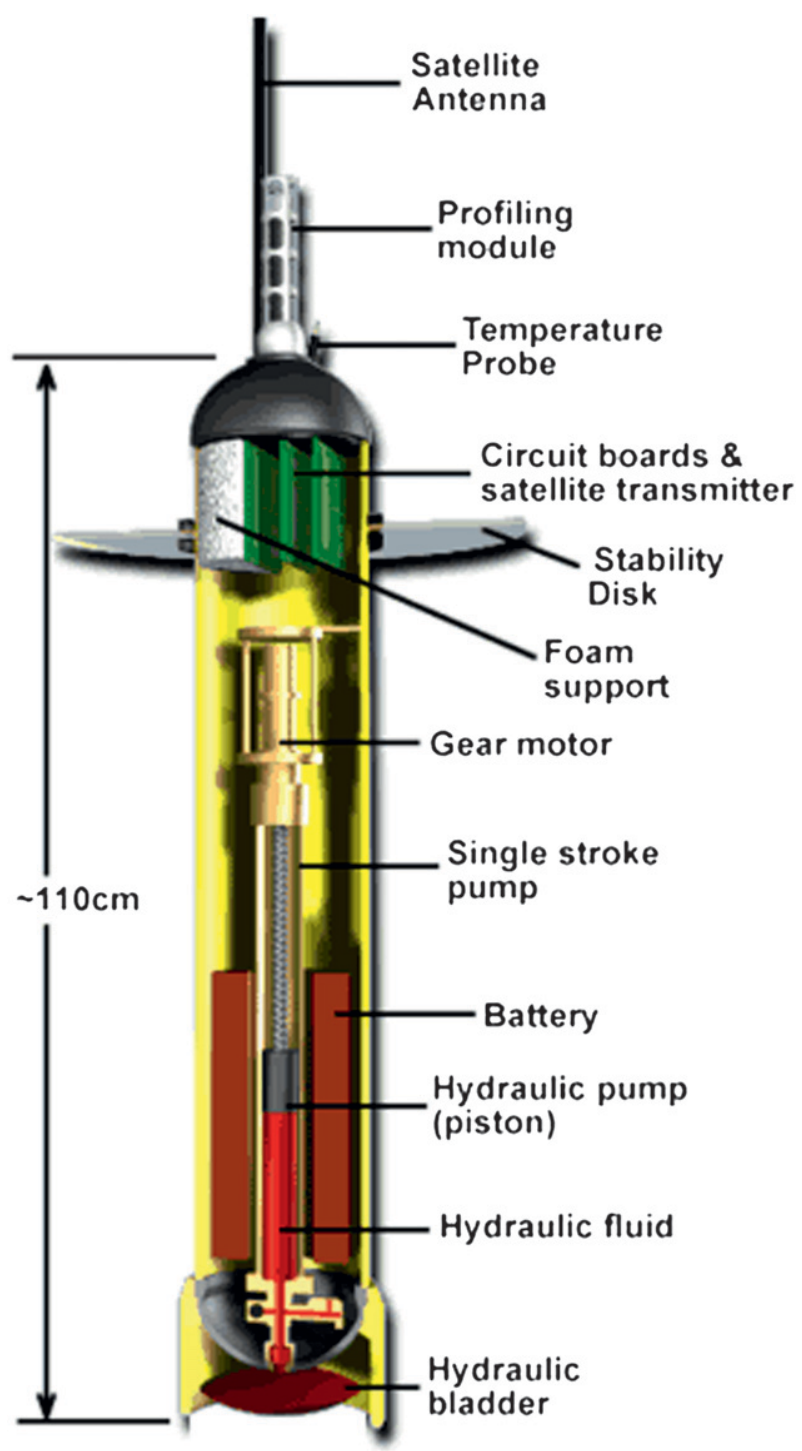

FIG. 2. Schematics of the APEX float (courtesy of the Argo web site).

\section{a. APEX floats}

The autonomous profiling explorer (APEX) float is designed and manufactured by Teledyne Webb Research (East Falmouth, Massachusetts). It uses an aluminum pressure case (16.5 $\mathrm{cm}$ in diameter and $110 \mathrm{~cm}$ long) and a hydraulic mechanism to stabilize it at a prescribed depth (Fig. 2). Each instrument is tailored and its mission programmed by the manufacturer, depending on the final user's desires.

Four parameters are essential for the APEX mission (Fig. 3): DOWN TIME, UP TIME, PARK PRESSURE, and DEEPEST (profile) PRESSURE.

DOWN TIME comprises the descent from the surface, the float drift at its park pressure, and the (possible)

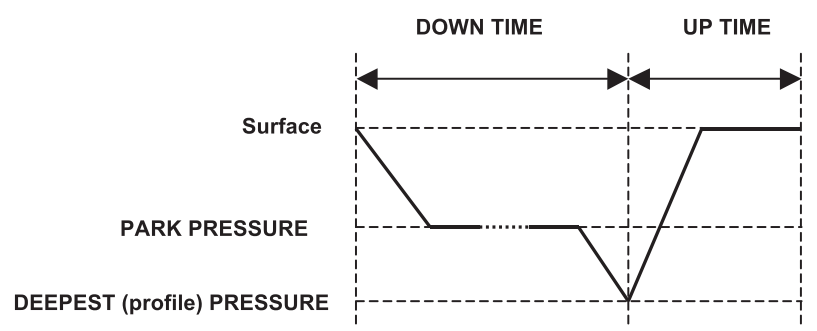

FIG. 3. APEX basic cycle parameters.

descent to its deepest profile pressure. UP TIME comprises the ascent from the deepest profile pressure and the surface drift with the ARGOS (or Iridium) transmission. Thus, APEX cycles are DOWN TIME + UP TIME long. APEX can also go deeper only once every $N$ cycles, as illustrated in Fig. 4 for $N=2$.

Prior to the first dive, APEX stays for a short time (usually $6 \mathrm{~h}$ ) at the surface and continually transmits test messages, which contain the mission parameters. Then, the float begins its mission proper, cycling until battery exhaustion. At the end of each cycle, a number of data messages (approximately proportional to the profile size) are sent repeatedly for several hours (usually $12 \mathrm{~h}$ ).

During the (underwater) drift, APEX regularly measures $p, t$, and $S$ triplets but generally only the last one (sampled at the end of the parking phase) is transmitted. Newer APEX versions (APF9 and onward), however, also transmit statistics for $p$ and $t$ regularly sampled during the parking phase. Only a few float versions transmit all the park measurements (but without corresponding times that can however be estimated later). Figure 5 gives an example of the park $p$ and $t$ values measured during an APEX mission south of the Drake Passage. Figure 6 confirms that during five cycles the bathymetry was shallower than the float nominal park pressure. These grounded cycles will be excluded in ANDRO.

During ascent (ascent rate of $\sim 10 \mathrm{~cm} \mathrm{~s}^{-1}$ ), APEX measures $p, t$, and $S$ at $1 \mathrm{~Hz}$ and averages the values within predefined pressure bins (the so-called depth table). Surface pressure $\left(p_{\text {surf }}\right)$ is measured before descent (at the end of the previous cycle) and used to stop the CTD measurements on ascent as soon as $p<\max \left(4 \mathrm{dbar}, p_{\text {surf }}+5 \mathrm{dbar}\right)$. None of the transmitted pressure values is corrected using $p_{\text {surf }}$.

Because of the several user customizations (and frequent evolutions), there are many APEX firmware versions. Actually, 86 APEX decoders were developed to process the raw Argos data.

There are two different Argos message types: one for the test message(s) and another one for the data messages. 


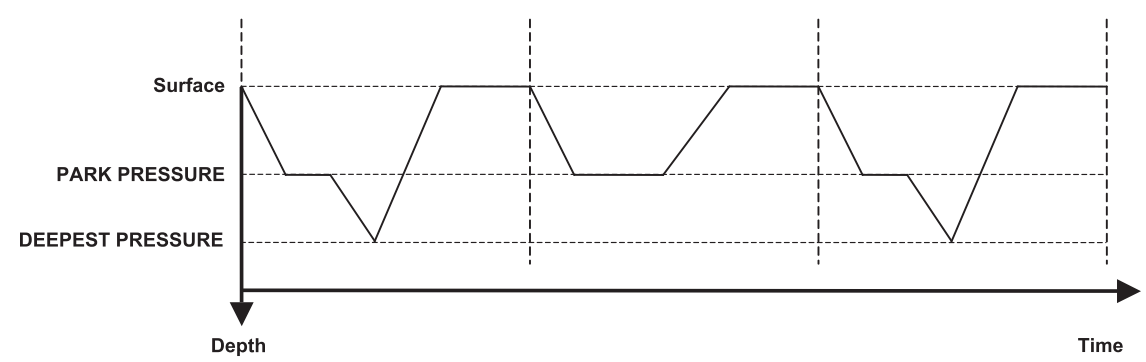

FIG. 4. APEX deep profiling every two cycles.

The test message(s) generally contains the float serial number and software revision, the time elapsed since startup, the mission parameters, and some other technical information (battery voltage, piston position, etc.). There are one, two, or three different test messages depending on the float version.

The number of data messages transmitted for each cycle depends on the amount of data collected. If $M$ messages are necessary, they will be transmitted iteratively until the end of the UP TIME period. Message number 1 mainly contains technical information (e.g., the profile number), while the other messages contain the $p, t$, and $S$ values.

\section{b. SOLO floats}

The SOLO floats come in two models: the WHOI SOLO, developed at the Woods Hole Oceanographic Institution in Massachusetts, and the SIO SOLO (Fig. 7), developed at the Scripps Institution of Oceanography in California (both models contribute equally to the
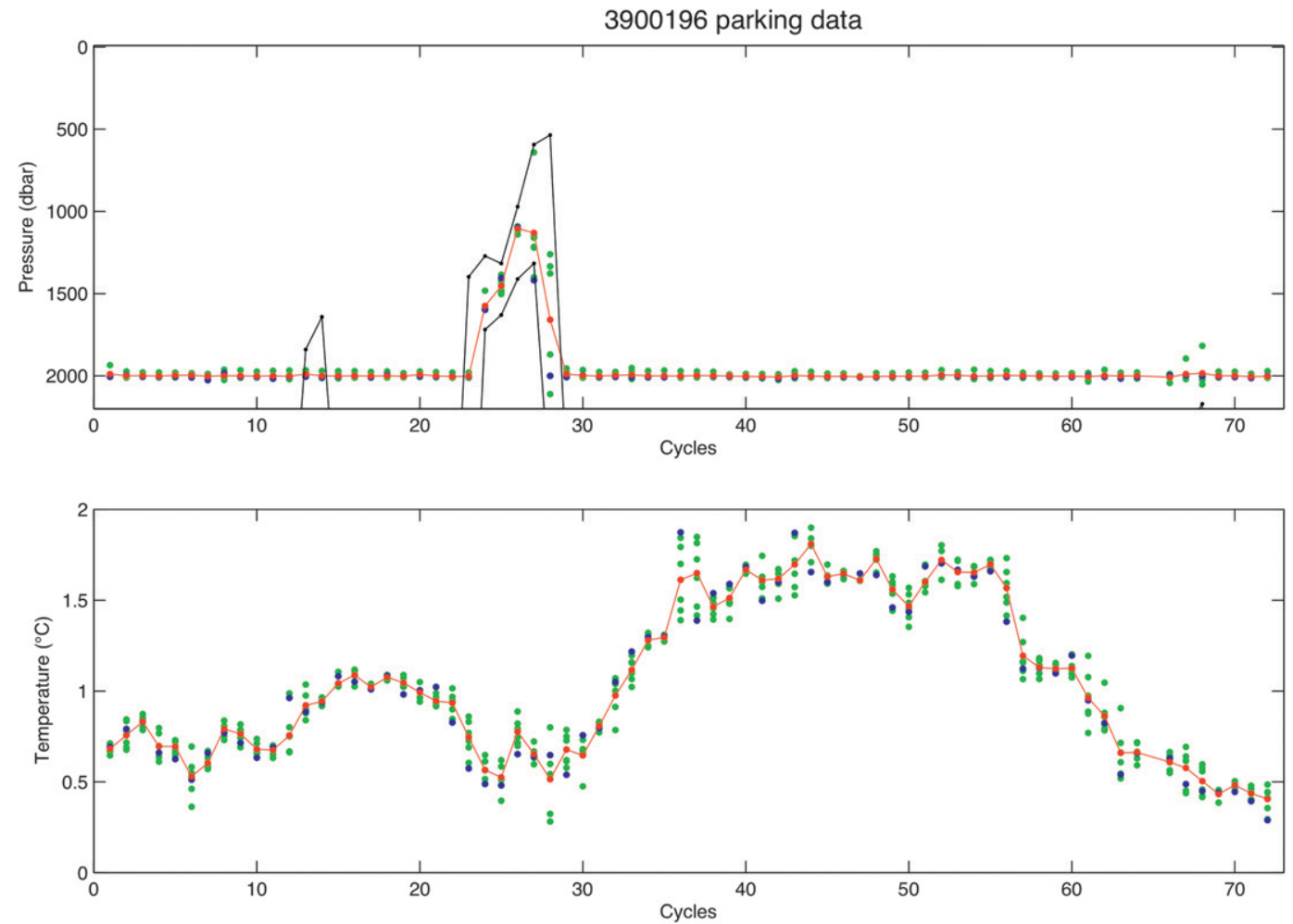

FIG. 5. WMO 3900196 APEX float (top) park pressures and (bottom) temperatures. This float was launched near Antarctica on 25 Nov 2003 and performed 72 cycles at 2000 dbar, every 10 days. There are six spot values every $40 \mathrm{~h}$ (green dots) during drift at parking depth (average is given by the red dot) and a final park measurement just before profiling (blue dot). Shallowest and deepest bottom depths are indicated in the top panel (they come from ETOPO5 at the float surface positions). Part of the trajectory is given in Fig. 6. 


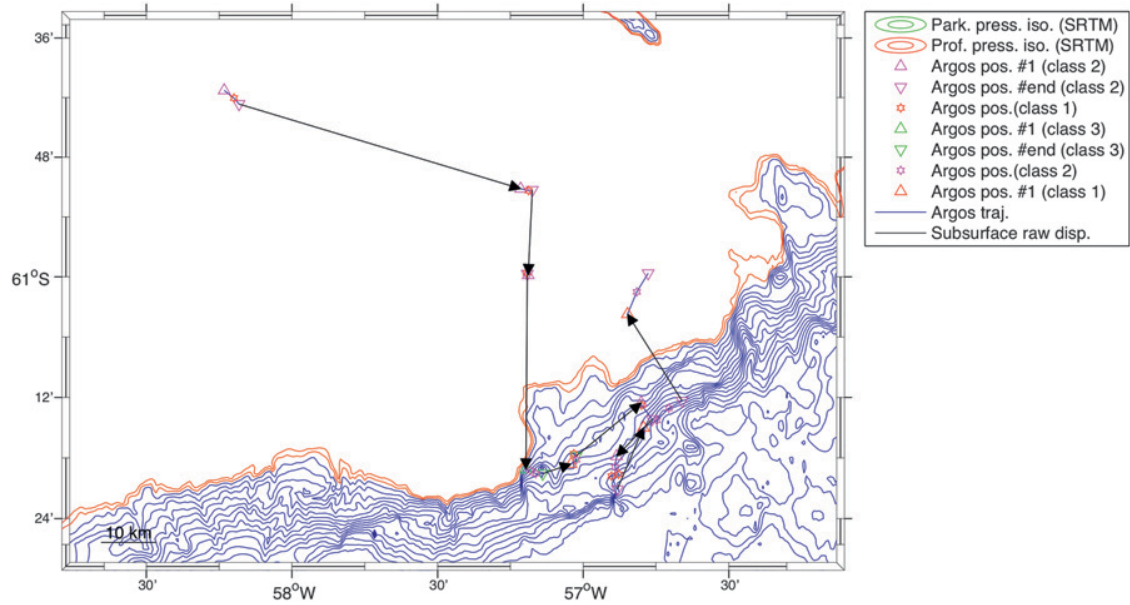

FIG. 6. WMO 3900196 APEX float displacements for cycles 21-28. Nominal park and deepest (profile) pressure are identical (2000 dbar). Black arrows give the estimated deep displacements (given in ANDRO). Isobaths at 1970 and $2030 \mathrm{~m}$ (red) come from SRTM30+. Shallower depths (every $100 \mathrm{~m}$ ) are in blue. During cycles 24-28, the float hit the bottom.

Argo fleet). These floats share the same pressure case with APEX. However, the user must program each float mission.

\section{1) WHOI SOLO}

For WHOI SOLO, each cycle is exactly $N$ days long (10 days generally) and the time reference is at the beginning of the parking phase, which is always at $0 \mathrm{~h}$ (midnight), when the float is supposed to have reached its park pressure (Fig. 8).

The drift phase is Dr hours long (generally 8 days and $5 \mathrm{~h}$ ). The float then descents to its DEEPEST (profile) PRESSURE, which should be reached within Dm hours (generally $4 \mathrm{~h}$ ). Thus, with the example given, the float Ascent Start is 8 days and $9 \mathrm{~h}$ [plus a variable waiting time (Wt)] after Descent End, whether or not the deepest profile pressure was reached. The time necessary for profiling is quite similar to that for APEX since the vertical float velocity is also of the order of $10 \mathrm{~cm} \mathrm{~s}^{-1}$. Argos transmission lasts exactly $\mathrm{Su}$ hours (generally $12 \mathrm{~h}$ ). During the drift phase, the float acquires $6 p$, $t$, and $C$ (or $S$ ) triplets, if equipped with Falmouth Scientific Inc. (or Sea-Bird Electronics) sensors. The first and last triplets are taken at the beginning and end of the parking phase (thus 8 days and $5 \mathrm{~h}$ apart in our example). The four other triplets are measured 1 day $1 \mathrm{~h}, 3$ days $1 \mathrm{~h}$, 5 days $1 \mathrm{~h}$, and 7 days $1 \mathrm{~h}$ after the reference time. These are averages over the previous intervals.

There are three types of Argos messages: one for profile data, one for drift data, and one for engineering data.

The engineering message contains $p, t$, and $C$ (or $S$ ) at the beginning and end of the drift phase, given in full range.
In the drift message instead, the four other $p, t$, and $C$ (or $S$ ) triplets are given as remainders modulo of $409.6 \mathrm{dbar}, 4.096^{\circ} \mathrm{C}$, and $1.024 \mathrm{mS} \mathrm{cm}^{-1}$ (or psu) respectively. With each of these four triplets, a very useful parameter is also given modulo 4096: the variation of the float volume DV, counted as the number of turns of the piston driver. Actually, $\Delta$ Park Pres $=0.75 \mathrm{DV}$ to a high

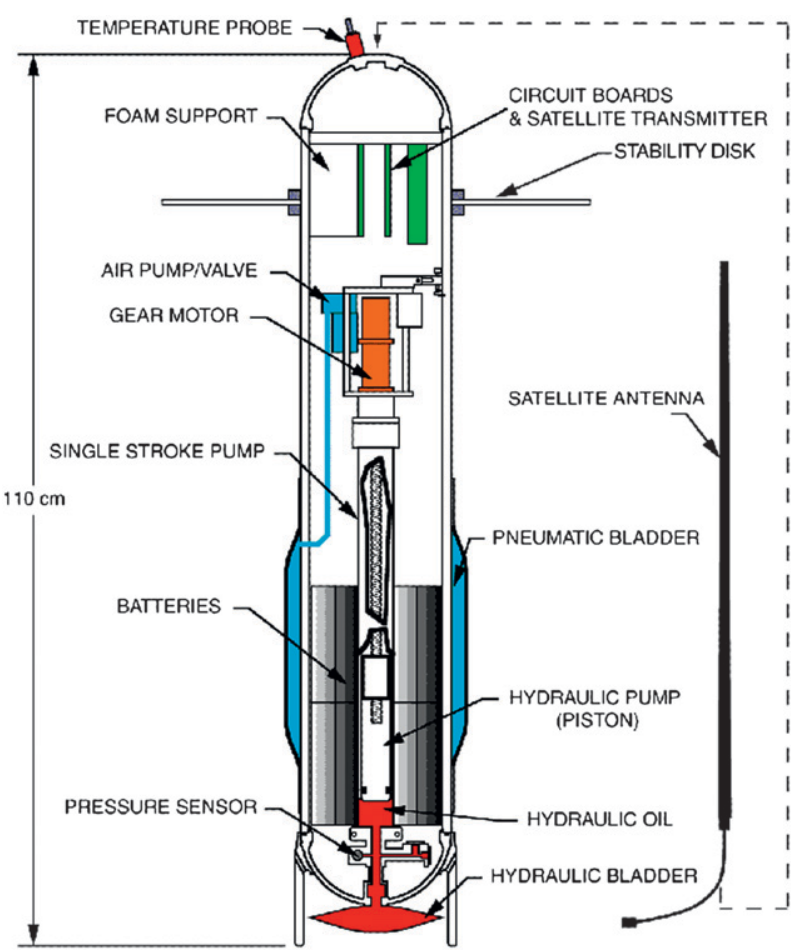

FIG. 7. Schematics of the SIO SOLO (courtesy of the Argo web site). 


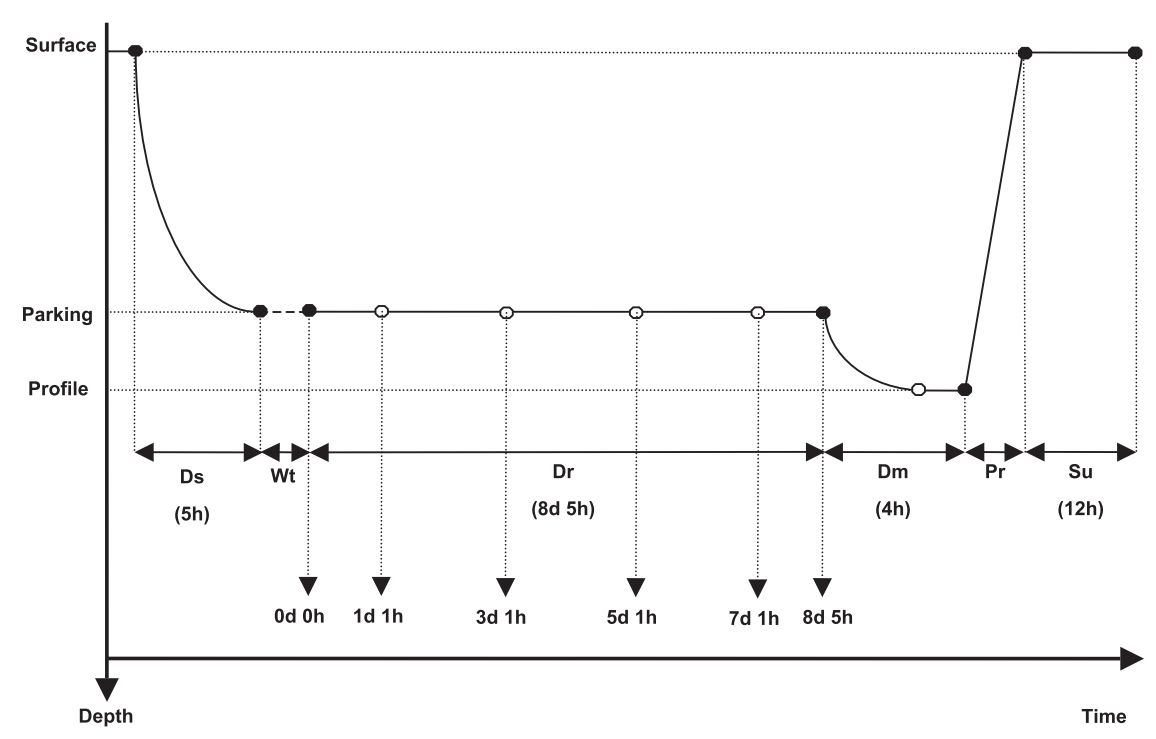

FIG. 8. Schematics of a cycle for the WHOI SOLO.

accuracy, and this enables us to solve the modulo uncertainties on the pressures measured during the drift phase.

In a profile message, the pressures are not transmitted and must be deduced from the predefined depth table and from the first and last bin pressure values transmitted in the engineering message. Nine $t$ and $C$ (or $S$ ) bin values (measured during ascent) are transmitted in a profile message (the first bin values are absolute, while the eight following ones are given as forward differences). The latter differences are given on 13 (11) bits and, thus modulo $\pm 4.096^{\circ} \mathrm{C}\left( \pm 1.024 \mathrm{mS} \mathrm{cm}^{-1}\right.$ or psu $)$.

\section{2) SIO SOLO}

The SIO SOLO functioning is rather different from the WHOI SOLO. All times except the rise time (for profiling) are fixed (Fig. 9). For example, with a mission at $1000 \mathrm{dbar}$ (parking depth), the fall time is generally $500 \mathrm{~min}$, followed always by two repositioning phases $5 \mathrm{~h}$ each (to get closer to the prescribed depth). The park time proper lasts 20 times a sampling interval (generally 20 times $557 \mathrm{~min}$ ). Descent to the deepest profile pressure is always $5 \mathrm{~h}$ long, after which the float ascends as fast as it can by completely moving out its piston

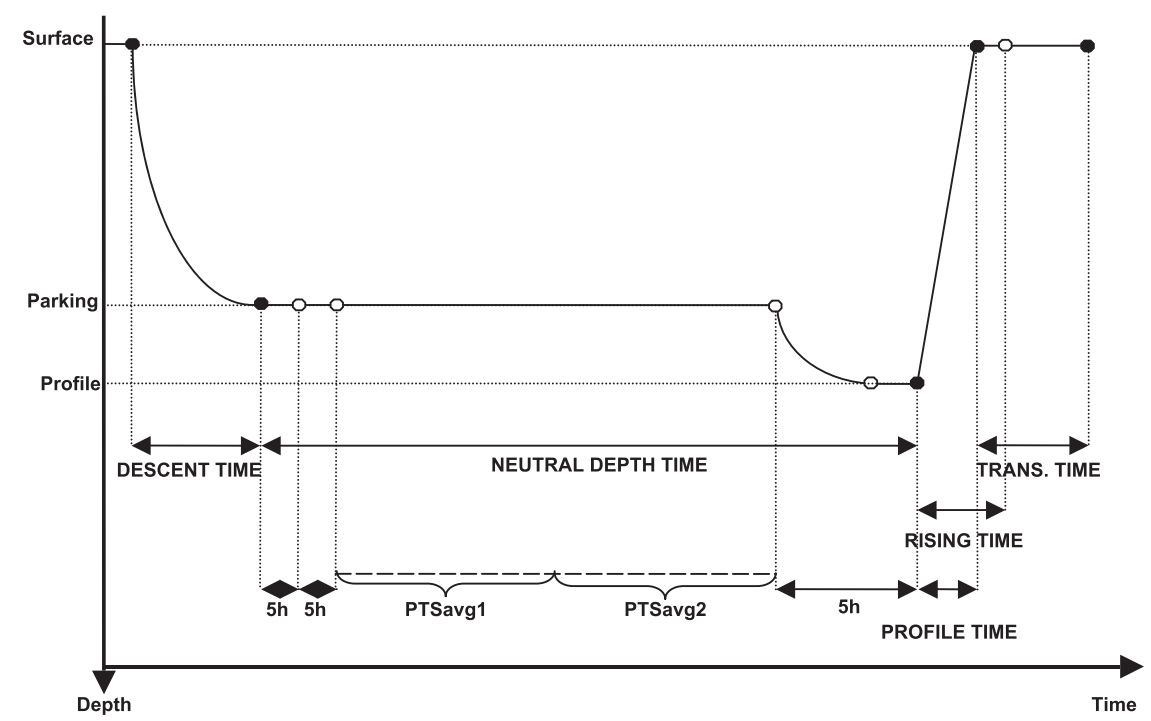

FIG. 9. Schematics of a cycle for the SIO SOLO. 

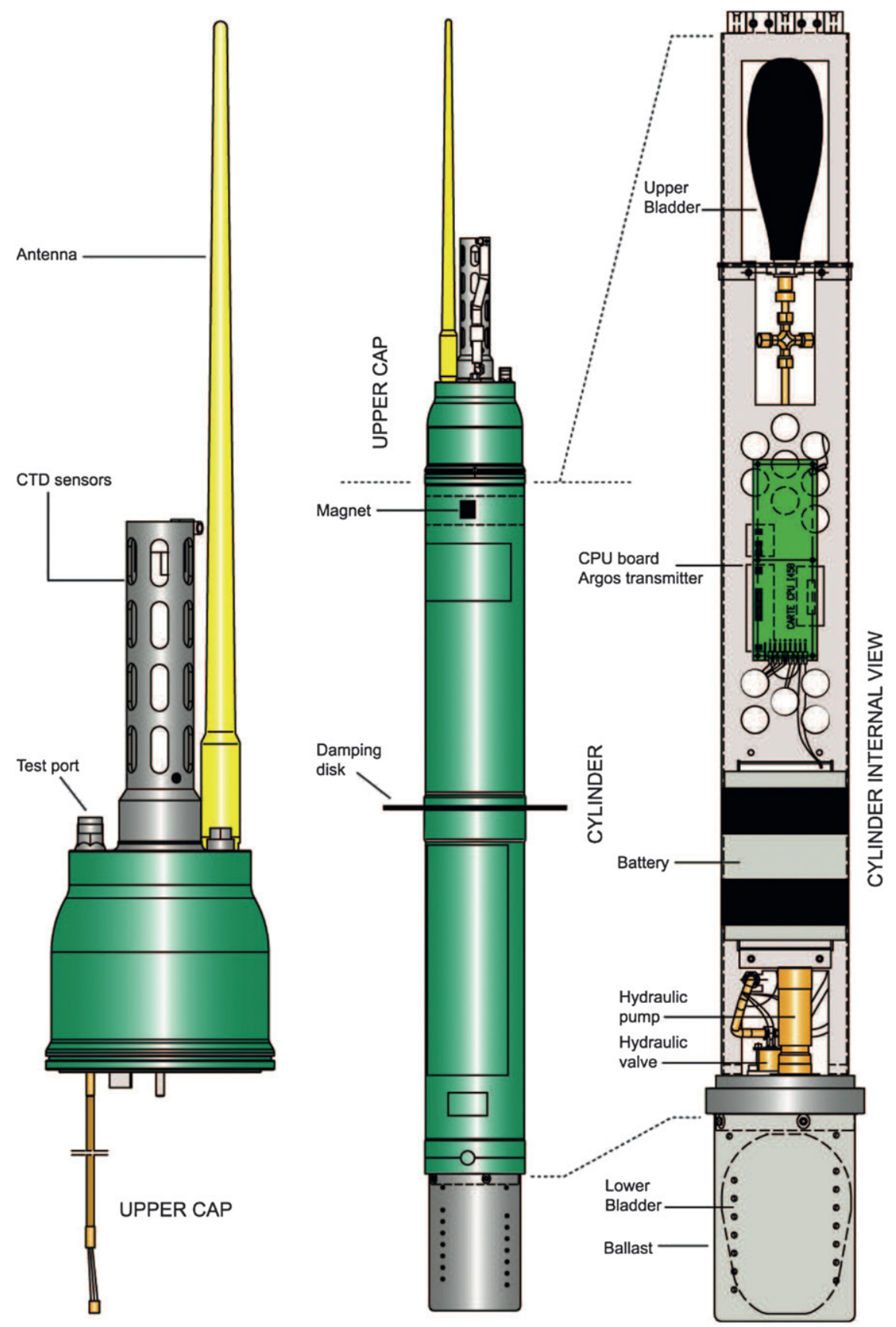

FIG. 10. Schematics of the PROVOR (CTS3 version, courtesy of NKE).

(a 1000-m rise takes roughly $2 \mathrm{~h}$ but this is slightly variable). Then, the float transmits its signal to Argos for a fixed duration (e.g., $18 \mathrm{~h}$ ). While drifting at its parking depth, 20 measurements of $p, t$, and $S$ are acquired but only the averages over the first 10 and last 10 readings are transmitted.

There are two different Argos message types: data messages for $p$, $t$, and $S$ measurements taken either during the parking or the profiling phases; and engineering messages for various parameters related to float functioning.

As of this time, we have developed two WHOI SOLO and three SIO SOLO decoders (all with Argos transmission).

\section{c. PROVOR floats}

This float is designed and manufactured by NKE (previously TEKELEC then MARTEC) in partnership 
6900386 (cycle \#19)
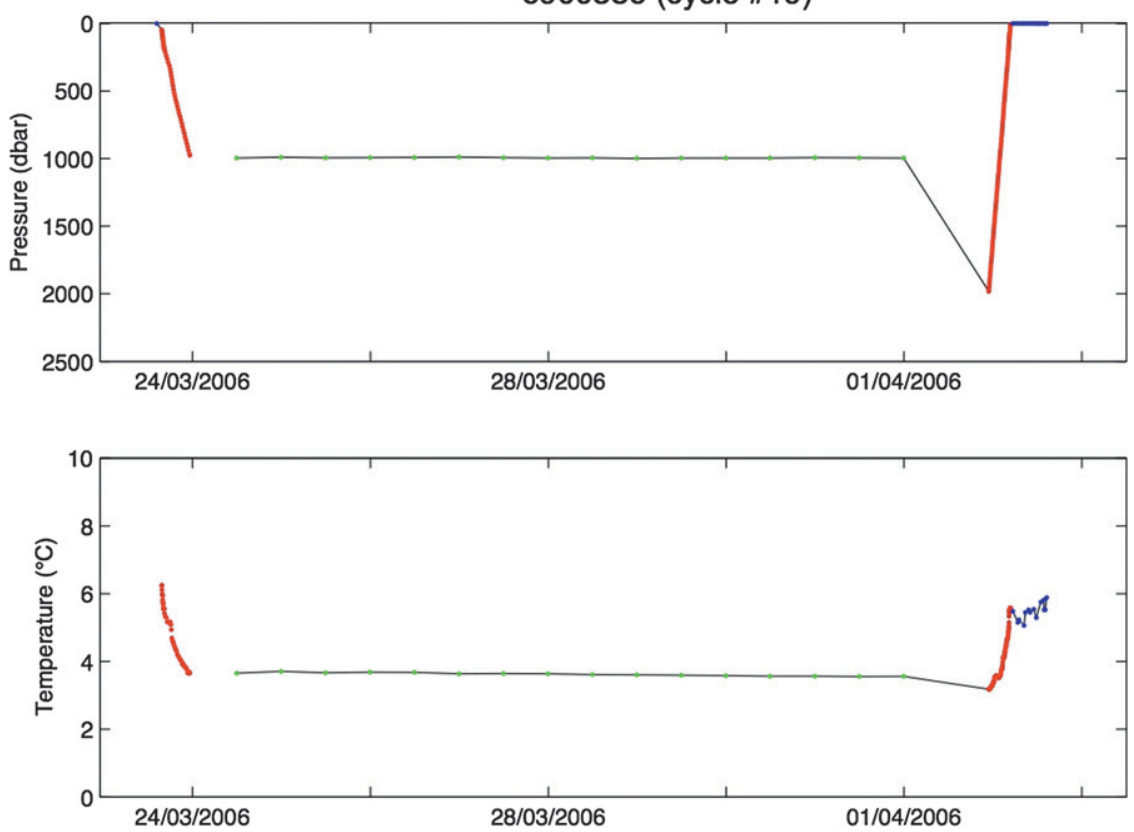

FIG. 11. WMO 6900386 PROVOR float (top) pressure and (bottom) temperature measurements during one cycle. Average descent velocity is $\sim 4 \mathrm{~cm} \mathrm{~s}^{-1}$, and the ascent velocity is $\sim 10 \mathrm{~cm} \mathrm{~s}^{-1}$. Blue, green, and red dots are, respectively, dated surface, parking, and profile measurements.

with the Institut Français de Recherche pour l'Exploitation de la Mer (IFREMER; see Fig. 10). It is slightly taller $(1.60 \mathrm{~m})$ than its American counterparts. The user must program each instrument mission. In addition, METOCEAN in Canada assembles its own PROVORs with a different software package.

Each cycle (except the first one) is $N$ days long and the reference time is at the beginning of the ascending profile (the day and hour of the reference time is programmable). PROVOR is controlled hydraulically to follow its park pressure within $30 \mathrm{dbar}$ and does $p, t$, and $S$ measurements every $H$ hours (generally every $12 \mathrm{~h}$ ) while drifting. All these measures are transmitted and approximately one among five is dated by the float clock. PROVOR ascent velocity is of the order of $10 \mathrm{~cm} \mathrm{~s}^{-1}$ (Fig. 11).

PROVOR Argos messages are of two types: technical and data messages. Technical messages contain information about the float functioning. Data messages come in three types: one for descending profiles (if required), another one for the parking phase, and a final one for ascending profile data. In each data message, because the measured parameters are given as absolute or relative values, there are between 5 and $7 p, t$, and $S$ triplets, with the first triplet dated. Open circles in Fig. 1 refer to the times given by PROVOR.

At this time, we have developed 23 different PROVOR decoder versions (including METOCEAN PROVORs and ARVOR, a new NKE float) using Argos transmissions and 4 versions using Iridium transmissions.

Figure 11 shows in situ measurements done during one PROVOR CTS2 cycle. Note that CTS2 floats always make surface temperature measurements. This particular one was also programmed to perform a descending profile.

\section{Data processing}

From the NetCDF public Argo files, we first generate a dataset, called DEP (for déplacement, meaning displacement in French) that comprises all the useful information given by the various floats. Then, the data are checked, corrected, and improved with information gathered outside or through a decoding of the original Argos or Iridium raw data files. Some complementary estimated data are also added. The final dataset is then used to generate the ANDRO deep displacements atlas. All these steps are detailed in this section.

\section{a. NetCDF Argo files}

Argo float data are available on both GDACs (ftp:// ftp.ifremer.fr/ifremer/argo/dac/ or ftp://www.usgodae. org/pub/outgoing/argo/dac/) using NetCDF format (http:// www.unidata.ucar.edu/software/netcdf/) as four different files, named wmo_meta.nc, wmo_prof.nc, wmo_traj.nc, 
and wmo_tech.nc, where wmo stands for the World Meteorological Organization number of the given float.

The "meta" file contains the float characteristics (e.g., Argos Platform Transmitter Terminal or PTT number, float serial number), the sensor characteristics (e.g., pressure gauge model with its calibration formula and coefficients), the deployment mission information (e.g., launch date and position), and the float mission description proper (in particular, the cycle duration, the nominal parking pressure, and the nominal deepest profile pressure).

The "prof" file contains all the profiles done during the float's lifetime. For each profile, general information is given [in particular, the cycle number and the profile direction (ascending or descending), time, and location], then the measurements are taken during the profiling (generally, $p, t$, and $S$ ). Individual profile files are also available in specific files.

The "traj" file contains for each cycle, the cycle times-DST, DET, AST, AET, and TST-of all the measurements made except during profiling, and the surface locations (and times).

The "tech" file contains, for each cycle, all the engineering data transmitted by the float. In particular, its serial number and software version, the pressure at the surface (not given in the traj file), the number of measurements done during parking or profiling, the float time, etc.

In the "prof" and "traj" files, all the parameter values have a quality control (QC) code. Note that bad data are preserved. Raw decoded data are always present and if corrections were made later on, adjusted values are also given. Actually, there are two possible levels of correction: a low-level automatic option (in real time) and a more sophisticated one (referred to as delayed mode) done by the principal investigator (PI) of the float mission.

\section{b. Original Argos and Iridium raw data}

Actually, the Argo NetCDF files are obtained through a decoding of the Argos or Iridium raw data. These data, which are not public, were kindly provided by the different DACs, so that we could do our own decoding (we managed to recover $98 \%$ of the original Argos raw data).

Argos raw data are provided as ASCII files by Collecte Localisation Satellites (CLS; in their format PRV DS; information online at http:/www.argos-system.org/ manuel/chapter 6.3.3) while Iridium data come either as short burst data (SBD) binary files (for PROVOR) or message and log ASCII files (for APEX).

\section{c. Original raw data preprocessing}

All Argos data were first concatenated to be sorted afterward by Argos PTT number. Then WMO float numbers are attributed to the data (sometimes one Argos PTT may have been consecutively shared by two or more different WMO numbers). Finally, the data are split into different cycles (there is one Argos raw data file for each received float cycle).

For Iridium PROVOR, one needs to associate the various SBD files corresponding to a given cycle.

\section{d. DEP dataset creation}

ASCII DEP files (there is one file for each float) are created from the public NetCDF (meta.nc, traj.nc, prof.nc, and tech.nc) files. Argos (or GPS) positions, dates, and location classes come from the traj.nc files together with the (real time) $p, t$, and $S$ measurements during the parking phase. Real-time $p, t$, and $S$ values sampled during each profile come from the prof.nc file. The launch position and date are recovered from the meta.nc file, as are a few other measurements from the tech.nc file, to be used in the future (for an improved version of ANDRO, see the discussion at the end of this paper).

\section{e. Additional Argos locations}

Examination of the Argos raw data files revealed that some Argos locations were not found in the traj.nc files. Missing positions (almost 3\% of the total) were added in the DEP files (sometimes improving the accuracy of existing files because of a better location class).

\section{f. Argos or Iridium data decoding}

At the beginning of this work (in 2007), we discovered several errors in the physical parameters given in the NetCDF files possibly due to unreliable decoding (e.g., rollover errors for $p, t$, and $S$ parking values). Thus, we decided to decode anew the Argos (or Iridium) raw data. All of the newly decoded data (in particular, park and profile $p, t$, and $S$ values) systematically replace the corresponding existing ones. Only if the original Argos data are not available do we keep the data imported from the NetCDF files.

All Argos floats (except SIO SOLO) have an error detection code embedded in the Argos messages (called CRC for cyclic redundancy check) that we have used to reject possibly corrupted messages. Furthermore, among all the received copies of a given transmitted message, the most redundant one is preserved. Doing so can reduce slightly the amount of preserved data, as compared with the original NetCDF files.

For the Iridium floats, checking of the messages is done very efficiently by the satellite system itself. 


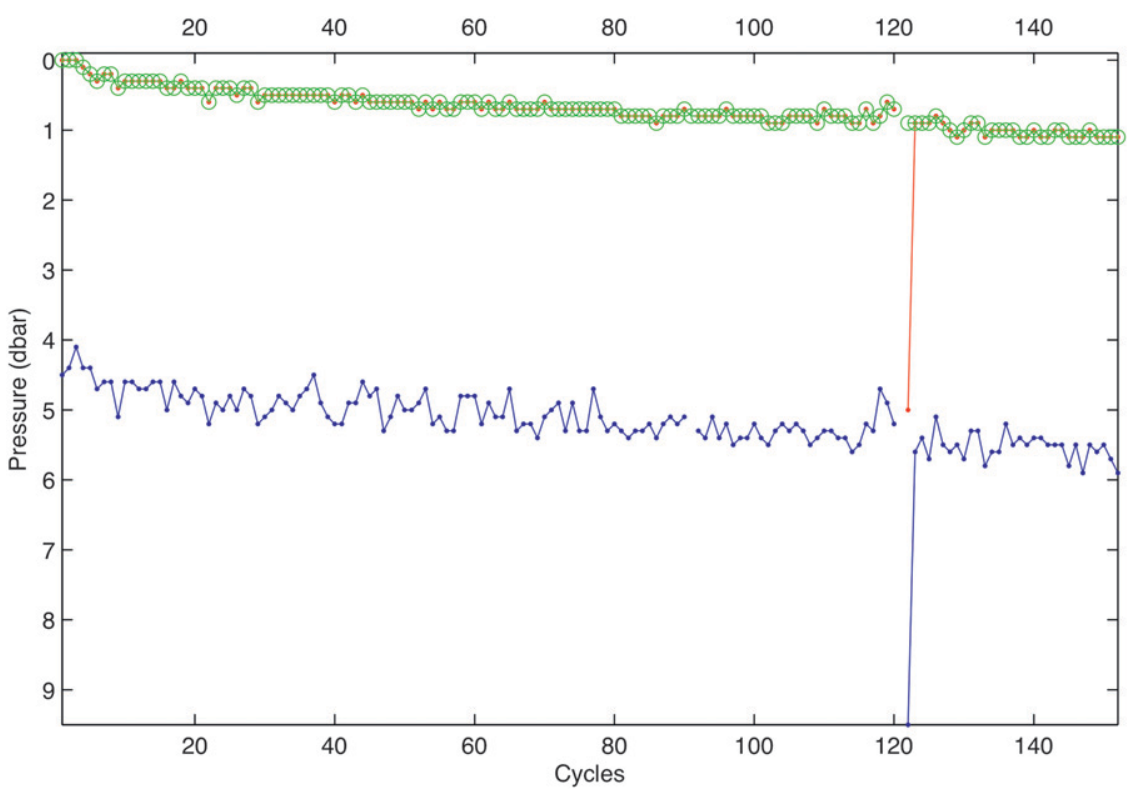

FIG. 12. Example of a surface pressure measurement done probably before the float has reached the surface (cycle 122). Original and corrected surface pressures are given by red and green dots, respectively. Uppermost profile pressures (blue dots).

\section{g. Meta data check}

At this stage, we were able to check the following parameters given in the meta.nc files:

- REPETITION_RATE, which gives the number of times the float performs the same cycle mission (defined by fixed CYCLE_TIME, PARKING_PRESSURE and DEEPEST_PRESSURE parameters);

- CYCLE_TIME (theoretical cycle duration);

- PARKING_PRESSURE (theoretical subsurface drifting pressure); and

- DEEPEST_PRESSURE (theoretical starting pressure of ascending profile).

These parameters (corrected if necessary) are stored in a separate file to be used in the following steps.

\section{h. Representative park pressure}

For each cycle, we determine a realistic estimate of the float parking depth, which is very important if we want to use Argo float deep displacements to track water motions.

This representative park pressure (RPP) is computed as follows:

- If the float provides several park pressure values, RPP is the (weighted) average value.

- If the float only provides the mean of (regularly sampled) park pressures, this is RPP.
- If the float provides only one park pressure (generally sampled at the end of the drifting phase), this is RPP.

- If the float provides the minimum and maximum pressures sampled during the drifting phase, the RPP is the middle value.

- If no pressure measurement is available during the drifting phase, RPP is given by the theoretical PARKING_PRESSURE value (in this case we need to check if the local bathymetry is not shallower and if the induced deep velocity seems realistic).

Then, a systematic visual check on the RPP time series is done to detect possible errors due to float pressure transducer malfunction (mostly on APEX) or transmission error. Existing RPP values are then replaced by a default value if the RPP is not correctable, 0 dbar if the float is obviously at the surface, or the theoretical PARKING_PRESSURE if the float seems to be working nominally.

\section{i. Cycle number check}

To be reliable for scientific use, a deep displacement must be defined between two consecutive cycles. Thus, it is very important to be confident in the cycle number. The check is easy with the APEX or METOCEAN floats because they transmit the cycle number in one Argos message. For most of the other floats, we need to crosscheck the Argos (or GPS) location dates with the CYCLE TIME parameter. 
TABLE 1. ANDRO (updated 29 November 2012) displacement depth repartition. These displacements are estimated from the first fix of the current cycle and the last fix of the previous cycle.

\begin{tabular}{lrr}
\hline \hline Parking pressure (dbar) & $\begin{array}{c}\text { Number of displacements } \\
\text { (6212 floats) }\end{array}$ \\
\hline $0 \leq P \leq 250$ & 19936 & $3.3 \%$ \\
$250<P \leq 750$ & 37446 & $6.2 \%$ \\
$750<P \leq 1250$ & 422136 & $69.6 \%$ \\
$1250<P \leq 1750$ & 65666 & $10.8 \%$ \\
$1750<P \leq 2250$ & 50595 & $8.3 \%$ \\
$2250<P \leq 2750$ & 82 & $0.0 \%$ \\
Undefined & 10258 & $1.7 \%$ \\
Total & \multicolumn{2}{c}{606119} \\
\hline
\end{tabular}

\section{j. Surface pressure check}

All floats give (for each cycle) a pressure measurement taken at the surface just before diving. Most floats, except APEX (and old versions of SIO SOLO and METOCEAN), do correct the pressure values sampled during a cycle with this surface offset (http://www. argodatamgt.org/content/download/5478/39874/file/ SurfacePressureCorrectionTable.xls). Thus, for the APEX floats, these surface pressure values must be checked before correcting all the measured pressures (there are sometimes transmission errors and pressure measurements not obtained at the surface, as well as obvious malfunctions of the pressure sensor). In the DEP file both the original and the corrected surface pressures for APEX are preserved. The correction proper is done iteratively as follows (with $i$ the current cycle number):

- if $p_{\text {surf }}(i)$ is missing, but not $p_{\text {surf }}(i-1)$ and $p_{\text {surf }}(i+1)$, $p_{\text {surf }}(i)$ is interpolated,

- if $p_{\text {surf }}(i-1)$ is missing, but not $p_{\text {surf }}(i)$ and $p_{\text {surf }}(i+1)$ and if $p_{\text {surf }}(i)-p_{\text {surf }}(i+1)>+1 \mathrm{dbar}$, then $\operatorname{psurf}(i)=$ $\operatorname{psurf}(i+1)$ (see example in Fig. 12).

- A visual check enables one to reject spikes greater than $1 \mathrm{dbar}$.

However, the DEP pressures have not been presently corrected with these checked surface pressures.

\section{k. Additional times}

For all floats, the FMT and LMT (recall definitions in Fig. 1) are recovered from Argos raw data.

For PROVOR, all the times transmitted are already in the DEP files (since the decoding step).

For APEX, one can estimate the AET, TST, and DST. The method used to obtain TST is given at the end of the paper (appendix B). AET is given as TST $-10 \mathrm{~min}$. DST is estimated from the maximum envelope of the LMT as $\operatorname{Max}_{i=1}^{N}$ [LMT $(i)-i \times$ CYCLE_TIME]. Park et al. (2005) propose a more sophisticated method, but it

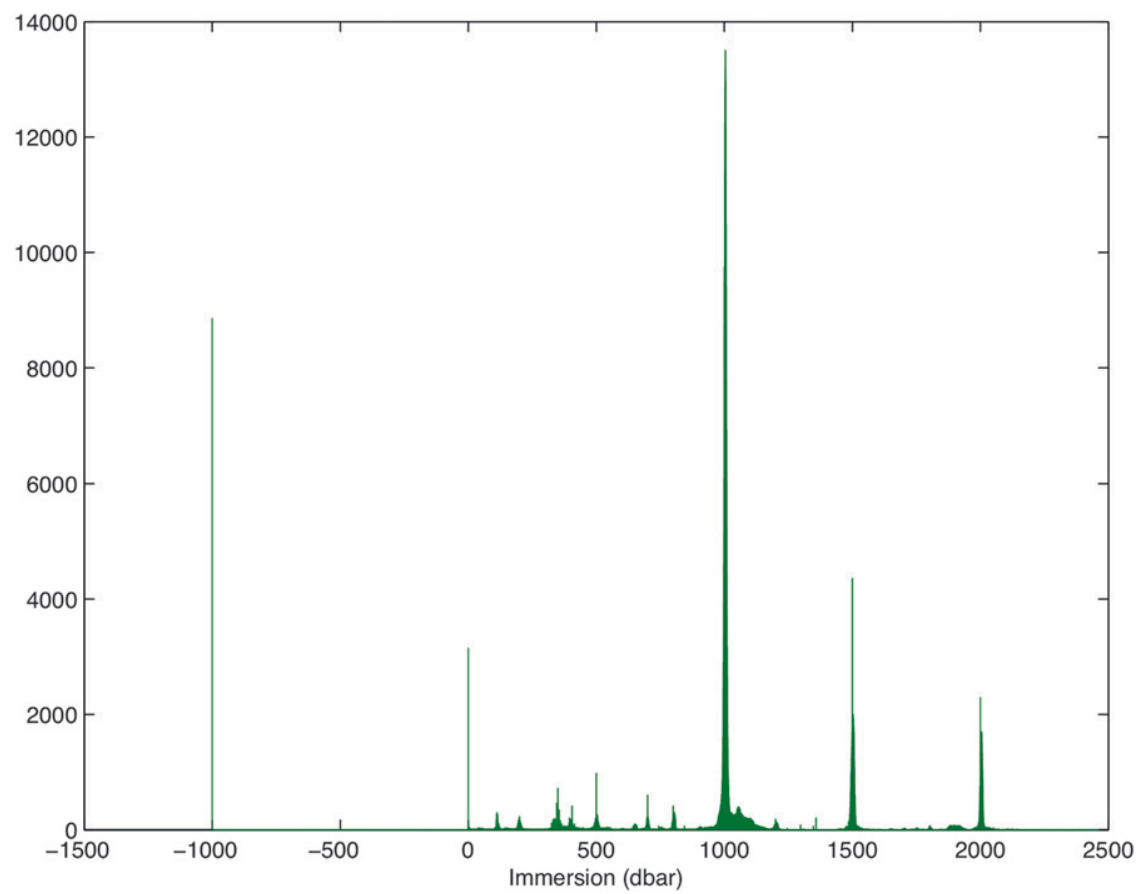

FIG. 13. ANDRO displacement depth repartition. Ordinate gives the number of displacements within 1-dbar layers. Unknown depths are set to the default value -999.9. 


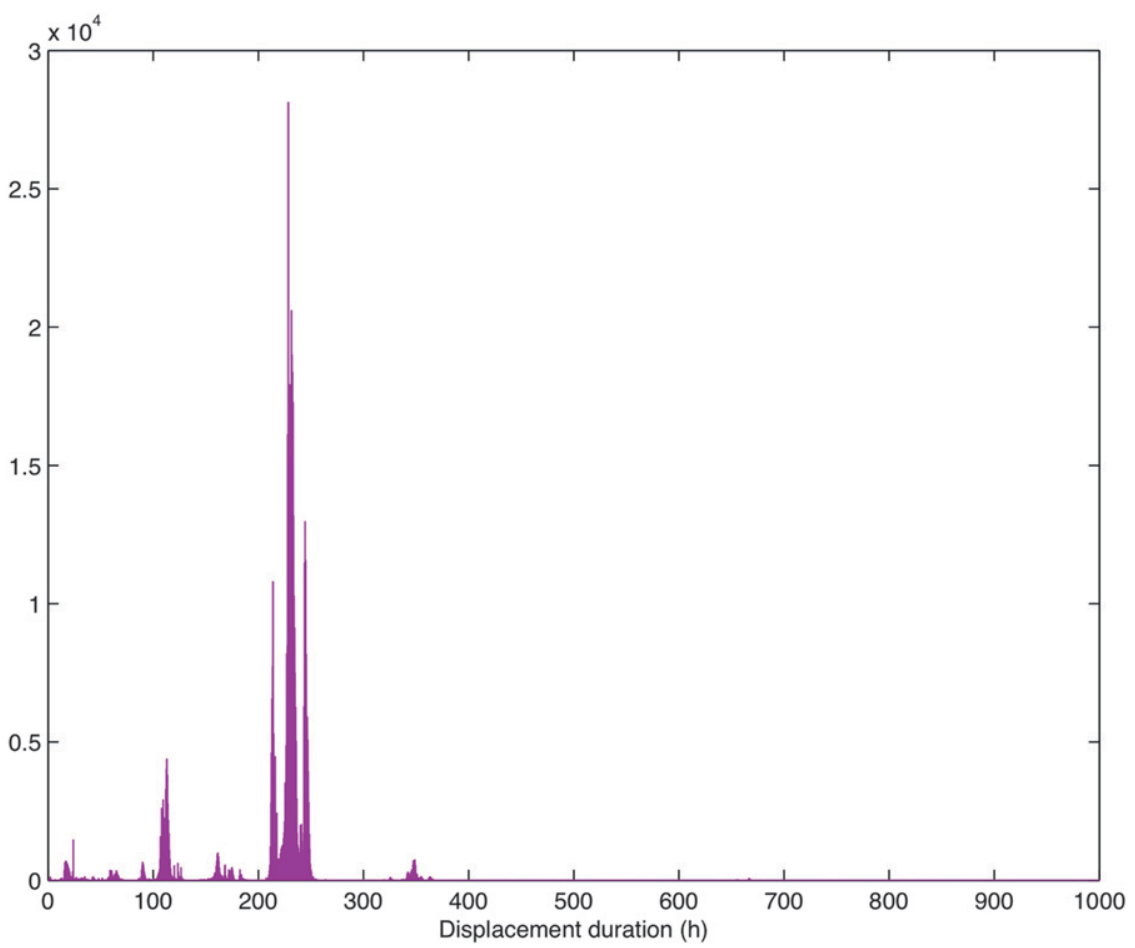

FIG. 14. ANDRO deep displacement durations.

is not suitable for floats profiling deeper than the park pressure.

For the other floats, no additional times have been estimated presently.

\section{l. Unusable cycles}

If a float hits the bottom while drifting, it is considered grounded, and this cycle is then flagged in the DEP file (to be excluded later from the ANDRO atlas). Grounded cycles are detected by visually comparing RPP with the National Aeronautics and Space Administration (NASA) Shuttle Radar Topography Mission (SRTM30+) worldwide bathymetric atlas (http://topex. ucsd.edu/WWW_html/srtm30_plus.html).

Some floats are recovered at sea or after beaching, while still functioning. The corresponding cycles are deleted from the DEP files.

\section{m. ANDRO generation}

From the final DEP files, one then generates the ANDRO atlas. In this first version, a deep displacement is defined as the orthodromic distance between the last Argos (or GPS) fix and the first Argos (or GPS) fix of two consecutive cycles. All GPS locations, but only Argos locations with classes 1, 2, or 3 (i.e., with roughly $1-\mathrm{km}, 350-\mathrm{m}$, or $150-\mathrm{m}$ accuracy, as given by Argos), are used. Furthermore, only those Argos positions that pass the Nakamura et al. (2008) test are preserved (appendix C). Grounded cycles are also excluded.

For each cycle, in addition to the locations and dates of the first and last fixes preserved, the (representative) park pressure and corresponding temperature are given together with the deep velocity components (deep displacement components over the time difference). For each cycle, two surface velocities are estimated: one over the first $6 \mathrm{~h}$ and the other over the last $6 \mathrm{~h}$ (if the time spent at the surface is less than $6 \mathrm{~h}$, these two surface velocities are equal). The surface speed distribution is given in the next section (see Fig. 17).

Due to possible negative surface pressure (caused by a pressure gauge drift), the park pressure may be negative when the float drifts near or at the surface. In that case, RPP is set to zero (original values are preserved in the DEP file).

For Iridium floats, if all the surface locations are within a circle of 100-m diameter (centered on the mass center location), the two surface velocities are put to zero if the time span is greater than $3 \mathrm{~h}$. For Argos floats, the circle diameter depends on the location classes of the first and last fixes: $1000 \mathrm{~m}$ if both fixes are of class 1 , $750 \mathrm{~m}$ if only one fix is of class 1 , and $350 \mathrm{~m}$ otherwise. Only 56 cycles gave zero surface velocities with the above criteria. 


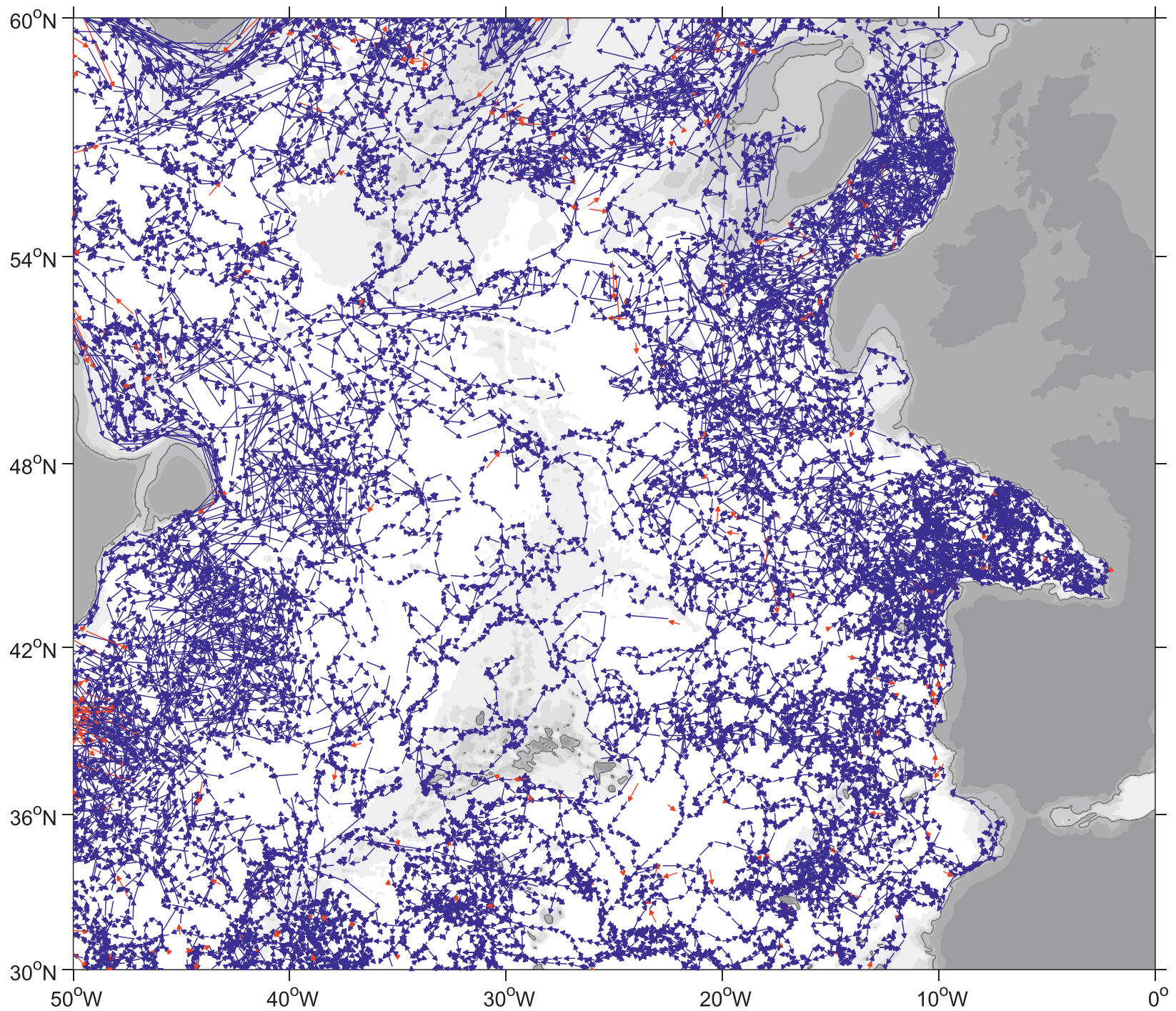

FIG. 15. ANDRO float displacements around 1000-m depth [actually in the (950, 1150)-dbar layer], in the northeast Atlantic. Red arrow corresponds to the first displacement of a given float.

When the surface velocity estimated is greater than $3 \mathrm{~m} \mathrm{~s}^{-1}$, it is defaulted.

The ANDRO atlas ASCII file consists of consecutive records (one record of 37 columns for each cycle), whose format is given in appendix A. Estimation of the errors on the deep and surface velocities, which are also given in ANDRO, is detailed in appendix A.

The structure of ANDRO is based on YoMaHa'07 (Lebedev et al. 2007), each line corresponding to an existing deep displacement or any of the two estimated surface velocities. Note that, in addition to these two surface velocities (YoMaHa'07 gives only the overall surface velocity), we have added the parking temperature and salinity (but the latter is not yet filled in ANDRO) and the float WMO number instead of their float ID.

\section{ANDRO actual contents}

The ANDRO atlas ASCII file [available online from the Coriolis or Laboratoire de Physique des Océans (LPO) web sites http://www.coriolis.eu.org/ or http:// wwz.ifremer.fr/lpo/, respectively) thus contains, presently, the float parking pressure (RPP) and temperature, deep and surface displacements, and associated times and deep and surface-associated velocities with their (roughly) estimated errors.

ANDRO (updated 29 November 2012) contains data from AOML, Coriolis, JMA, CSIRO, BODC, MEDS, INCOIS, KORDI, KMA, and CSIO, covering the time period from 10 September 1995 to 1 January 2010 (but before 1999 there are only very few displacements). 


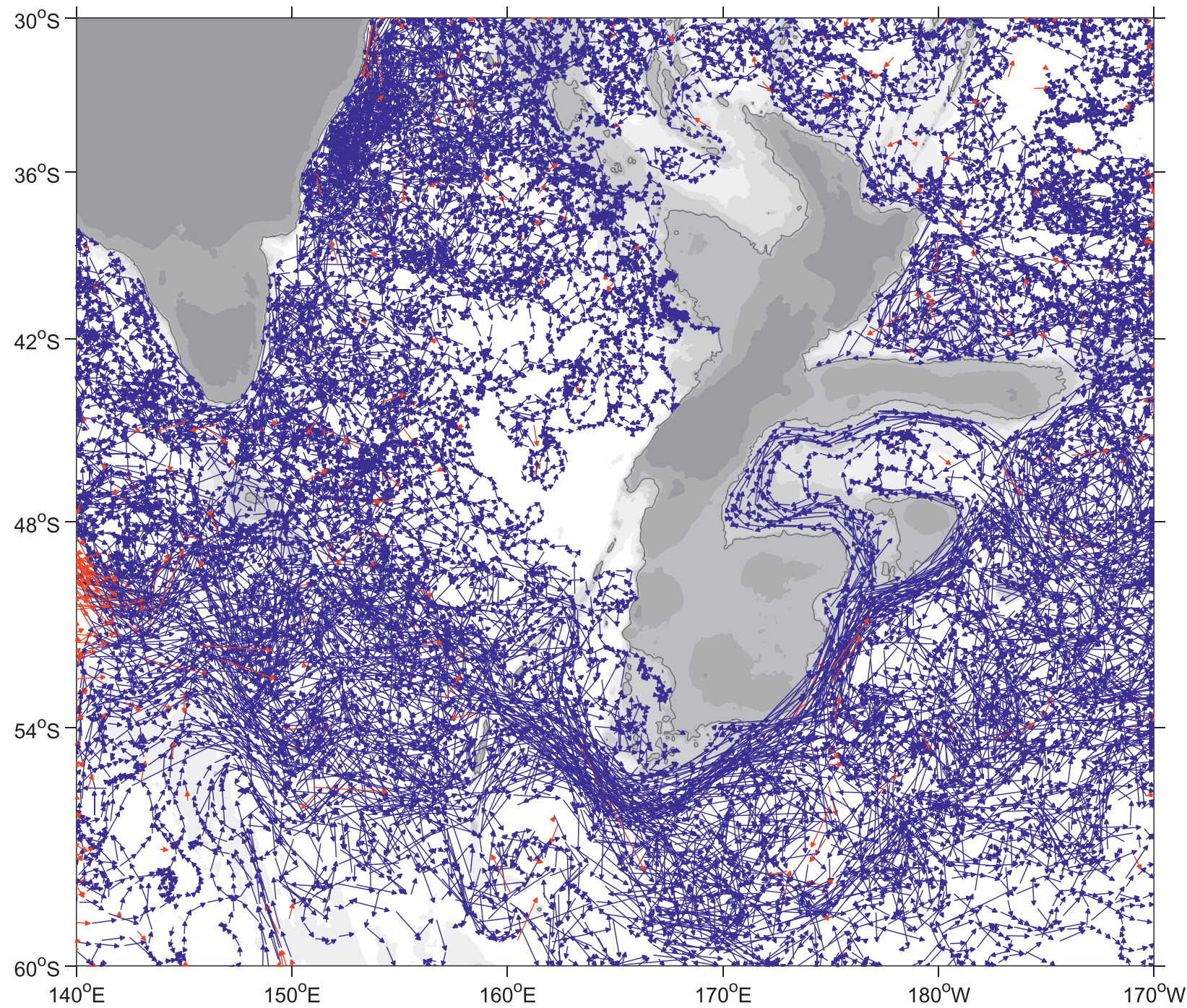

FIG. 16. ANDRO float displacements around 1000-m depth [actually in the (950,1150)-dbar layer], in the southwest Pacific. Red arrow corresponds to the first displacement of a given float.

There are a total of 6212 floats (Table 1) contributing 606119 displacements (over 626036 cycles done by a total of 6243 floats constituting the DEP dataset). However, results presented in the following do not include AOML data for the year 2009.

Figure 13 gives the displacement depth repartition. Most floats drifted near 1000 dbar, but there are noticeable contributions to deeper levels (near 1500 and 2000 dbar). A few floats remained at or close to the surface, due to erroneous programming but more generally some dysfunction of the float itself. As for the surface currents, they can be retrieved, if one wishes, through the Argos fixes (which are all given in the DEP files, available on the LPO web site).

Figure 14 gives the displacement duration distribution. Most floats cycled every 10 days (i.e., 240 h) with a mode near $230 \mathrm{~h}$; but some did cycle every 5 days. A few of the floats cycled every day, but obviously their deep displacements will be less reliable, because of the errors induced through the diving, surfacing, and the delay in locating the floats at the surface (see appendix A).

Figures 15 and 16 show in the [950, 1150]-dbar layer the vector displacements in the northeast Atlantic and in the southwest Pacific. The first displacement for a given float is plotted as a red arrow. The shallowest bathymetric line (corresponding to $950 \mathrm{dbar}$ ) is contoured in black. One may double-check here that no float happens to descend or surface over a shallower depth (but some may appear to cross the 950-dbar isobath because we do not know the float trajectory at depth). 


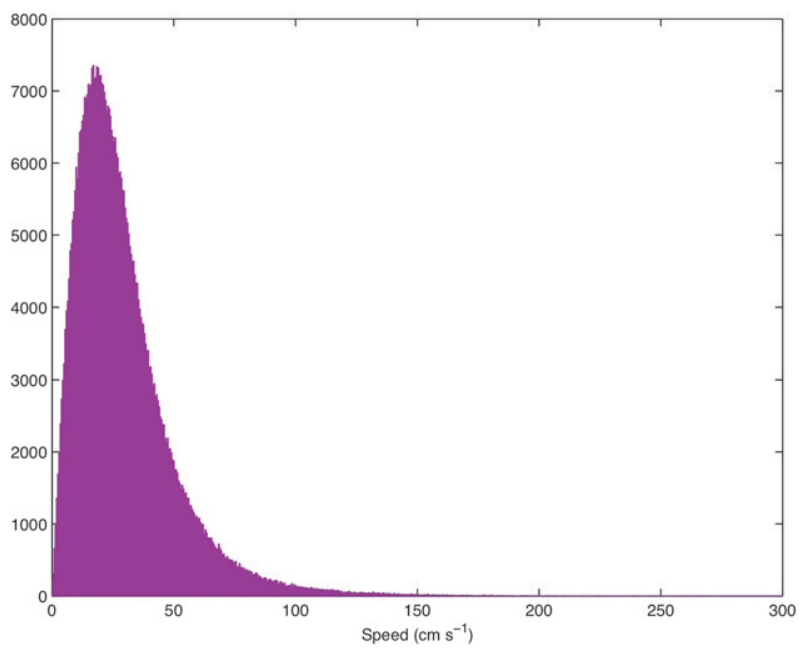

FIG. 17. Speed histogram of the surface velocities estimated from Argos locations recovered over at most the $6 \mathrm{~h}$ preceding the last location for a given cycle. Mean speed is $29.6 \mathrm{~cm} \mathrm{~s}^{-1}$ and standard deviation is $21.2 \mathrm{~cm}^{-1}$ (there are 533390 samples).

Figure 17 gives the distribution of the surface speed as obtained from the locations recovered during at most the $6 \mathrm{~h}$ preceding the last surface location of a given cycle (actually the distribution calculated from the $6 \mathrm{~h}$ following the first surface location is almost indistinguishable).

Figures 18 and 19 give the velocity histograms for the (950, 1150)- and (1850, 2050)-dbar intervals (for the whole ocean). Figure 20 compares the velocity distribution around 1000 and $1500 \mathrm{dbar}$, but only in the North Atlantic $\left(30^{\circ}-65^{\circ} \mathrm{N}, 80^{\circ} \mathrm{W}-0^{\circ}\right)$, where at both levels the

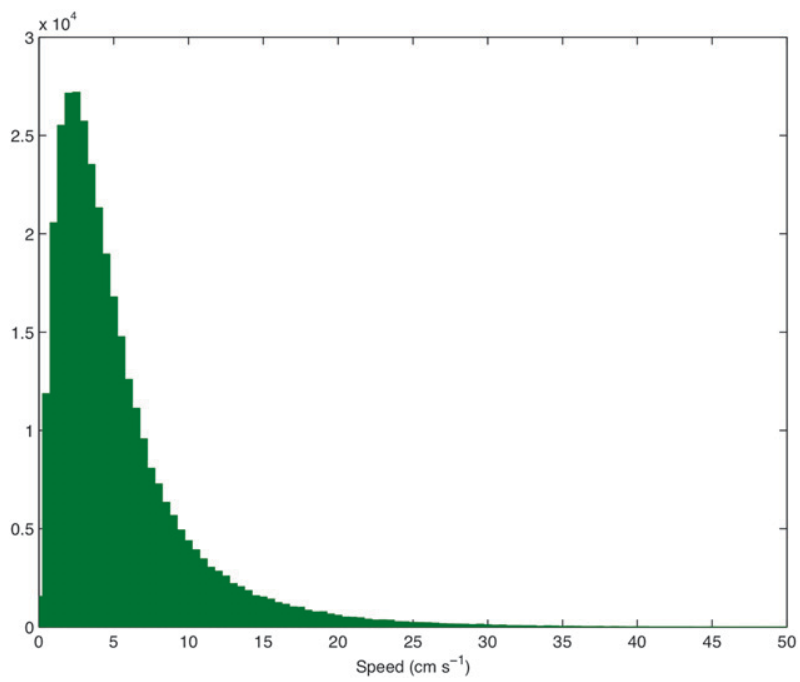

FIG. 18. Speed histogram for the $(950,1150)$-dbar layer, over the World Ocean. Mean speed is $5.4 \mathrm{~cm} \mathrm{~s}^{-1}$ and standard deviation is $4.8 \mathrm{~cm}^{-1}$.

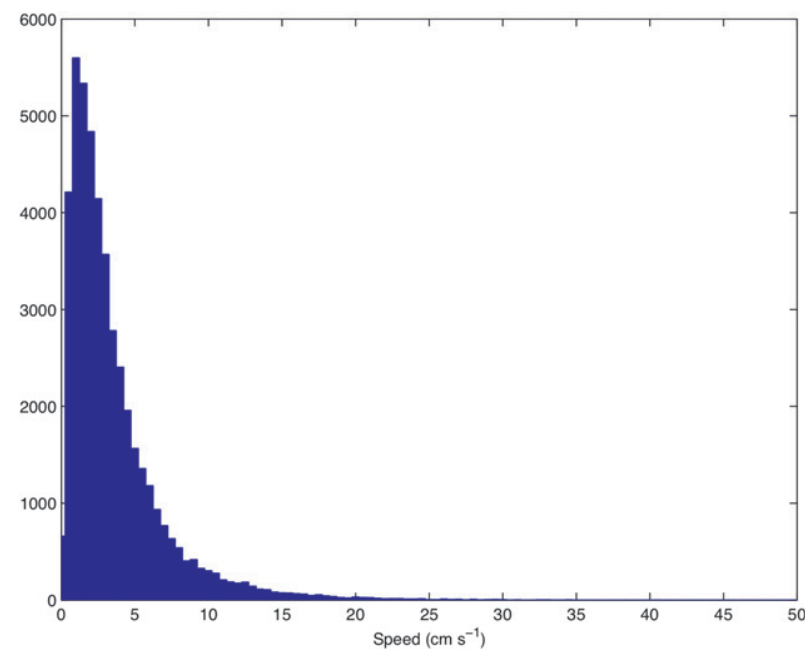

FIG. 19. Speed histogram for the $(1850,2050)$-dbar layer, over the World Ocean. Mean speed is $3.6 \mathrm{~cm} \mathrm{~s}^{-1}$ and standard deviation is $3.5 \mathrm{~cm}^{-1}$.

float densities are almost equal. One sees the clear weakening of the velocity under the main thermocline.

Time intervals between the first and last surface fixes have the repartition given in Fig. 21. The vertical bar at $0 \mathrm{~h}$ is due to the Iridium floats that normally report only one surface position (no surface current estimation). All other floats use the Argos system, and within $6 \mathrm{~h}$ more than $99 \%$ have been positioned twice (which is why we chose a 6-h time span to estimate the surface velocities mentioned before). There are only 143 cycles for which the surface time is greater than $30 \mathrm{~h}$. They mainly

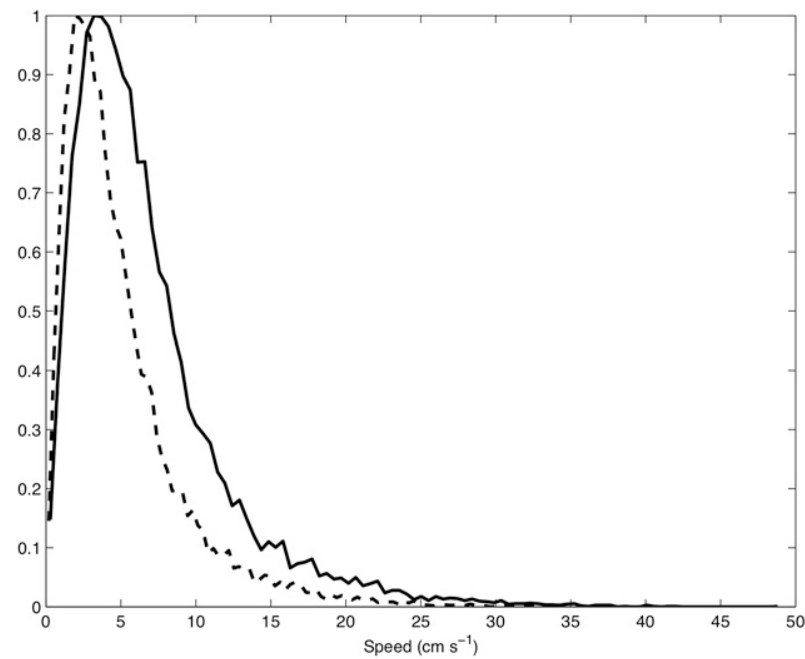

FIG. 20. Speed histograms for the $(950,1150)$-dbar layer (full line) and the $(1400,1600)$-dbar layer (dashed) over the North Atlantic $\left(30^{\circ}-65^{\circ} \mathrm{N}\right.$ and $\left.80^{\circ} \mathrm{W}-0^{\circ}\right)$. Mean speeds are 6.7 and $5.0 \mathrm{~cm} \mathrm{~s}^{-1}$ (standard deviations are 5.2 and $4.1 \mathrm{~cm} \mathrm{~s}^{-1}$ ), respectively. 


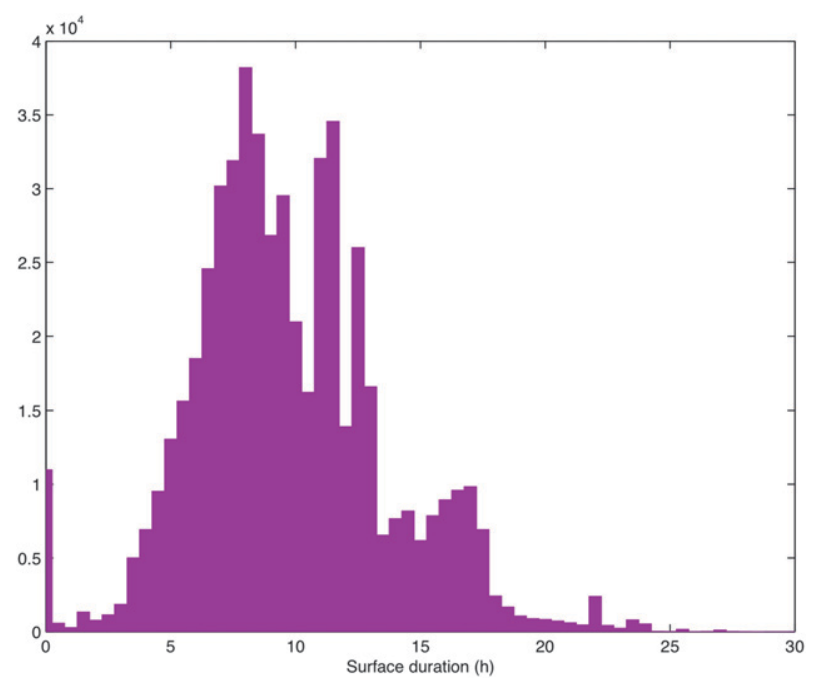

FIG. 21. Duration times at surface (i.e., intervals between first and last fixes)

correspond to floats that stay at the surface at the end of their life. They are then presumably surface current followers (near 0.5-m depth).

Figure 22 gives the number of fixes per cycle. For Argos floats, there are 11 fixes on average, roughly every hour during the time the floats stay at the surface $(10 \mathrm{~h}$ on average). The vertical bar at 1 fix corresponds in general to Iridium floats.

Figure 23 gives the number of displacements within $2^{\circ} \times 2^{\circ}$ boxes and for the $(950,1150)$-dbar interval.

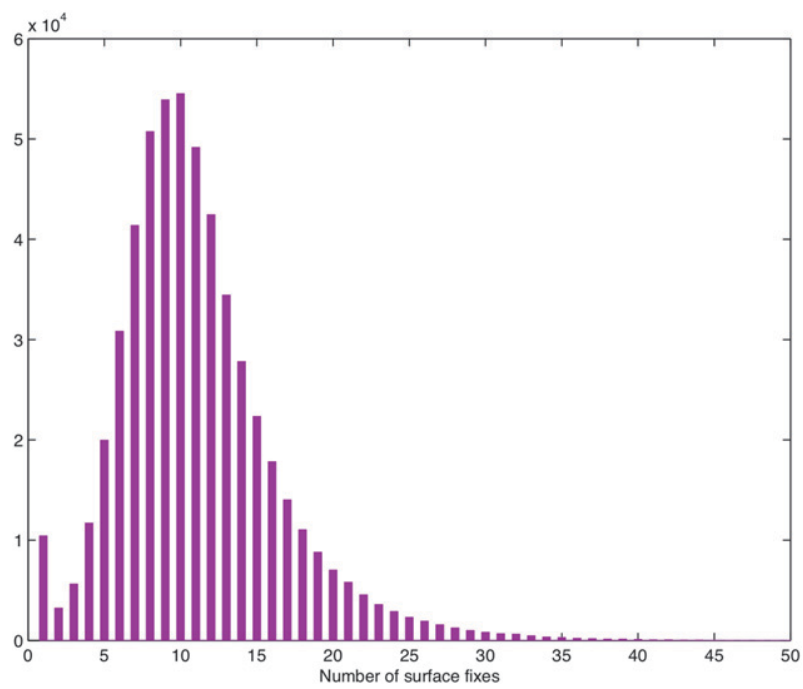

FIG. 22. Number of fixes per cycle.

Although the 1000-dbar level is the most populated, two other levels (around 1500 and 2000 dbar) contain useful data.

Figures 24 and 25 give the numbers of displacements within $2^{\circ} \times 2^{\circ}$ boxes for the $(1400,1600)$ - and (1850, 2050)-dbar intervals, respectively. Of course, for these two levels the float density is far from uniform (contrary to the 1000-dbar level).

As an illustration of the potential of the ANDRO atlas, Figs. 26 and 27 show the mean currents over
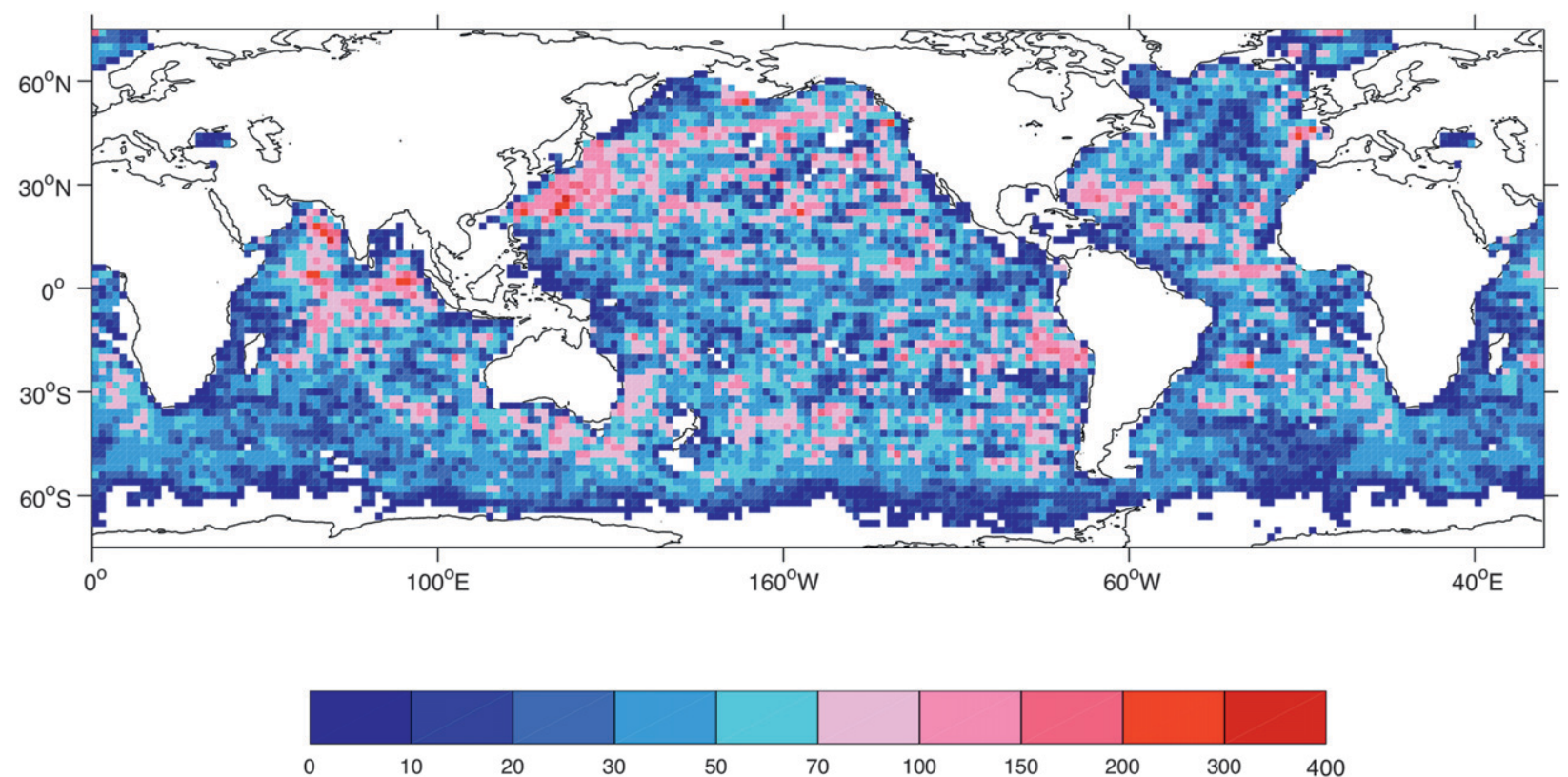

FIG. 23. ANDRO world displacement atlas for the $(950,1150)$-dbar layer. This constitutes $64.6 \%$ of the ANDRO data. 

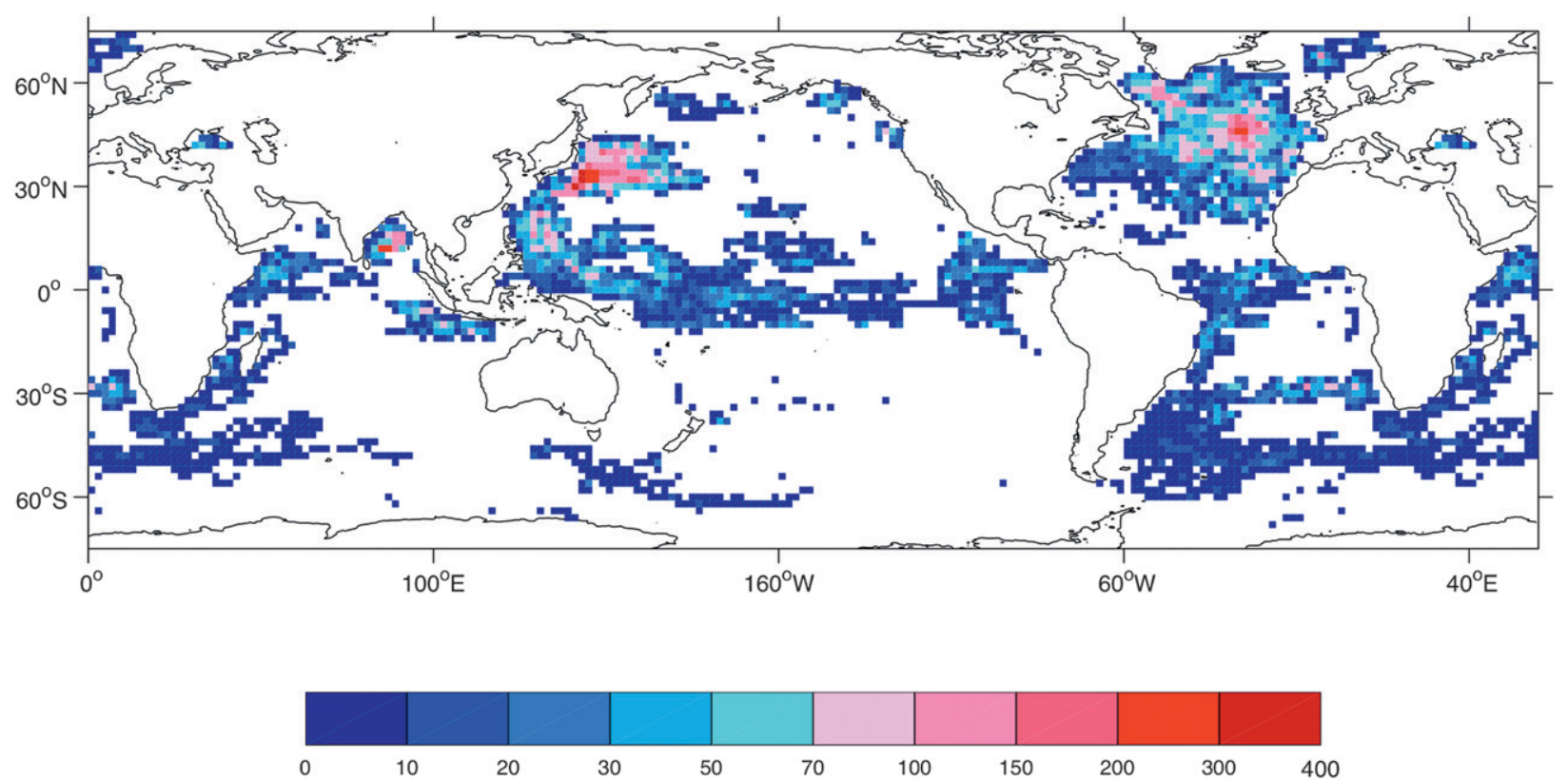

FIG. 24. ANDRO world displacement atlas for the $(1400,1600)$-dbar layer. This constitutes $11.1 \%$ of the ANDRO data.

circular areas (150-km diameter) centered every degree in latitude and longitude for the Northern and Southern Hemispheres, for the (950, 1150)-dbar layer. Actually, these mean currents are plotted as displacements over 60 days (to avoid a velocity scale). Red arrows flow eastward, blue arrows westward. The main features of the general circulation are clearly revealed: strong western boundary currents, alternating jets in the equatorial region (particularly in the Pacific), and the strength of the
Antarctic Circumpolar Current (ACC). Moreover, mean currents in the interior tend to be zonal. Mean currents were estimated with at least 30 float days within the 150-km-diameter disks.

\section{Comparison between ANDRO and YoMaHa'07}

For a comparison between the ANDRO and YoMaHa'07 (updated on 6 June 2012) datasets, we used the 5889 floats contributing deep displacements
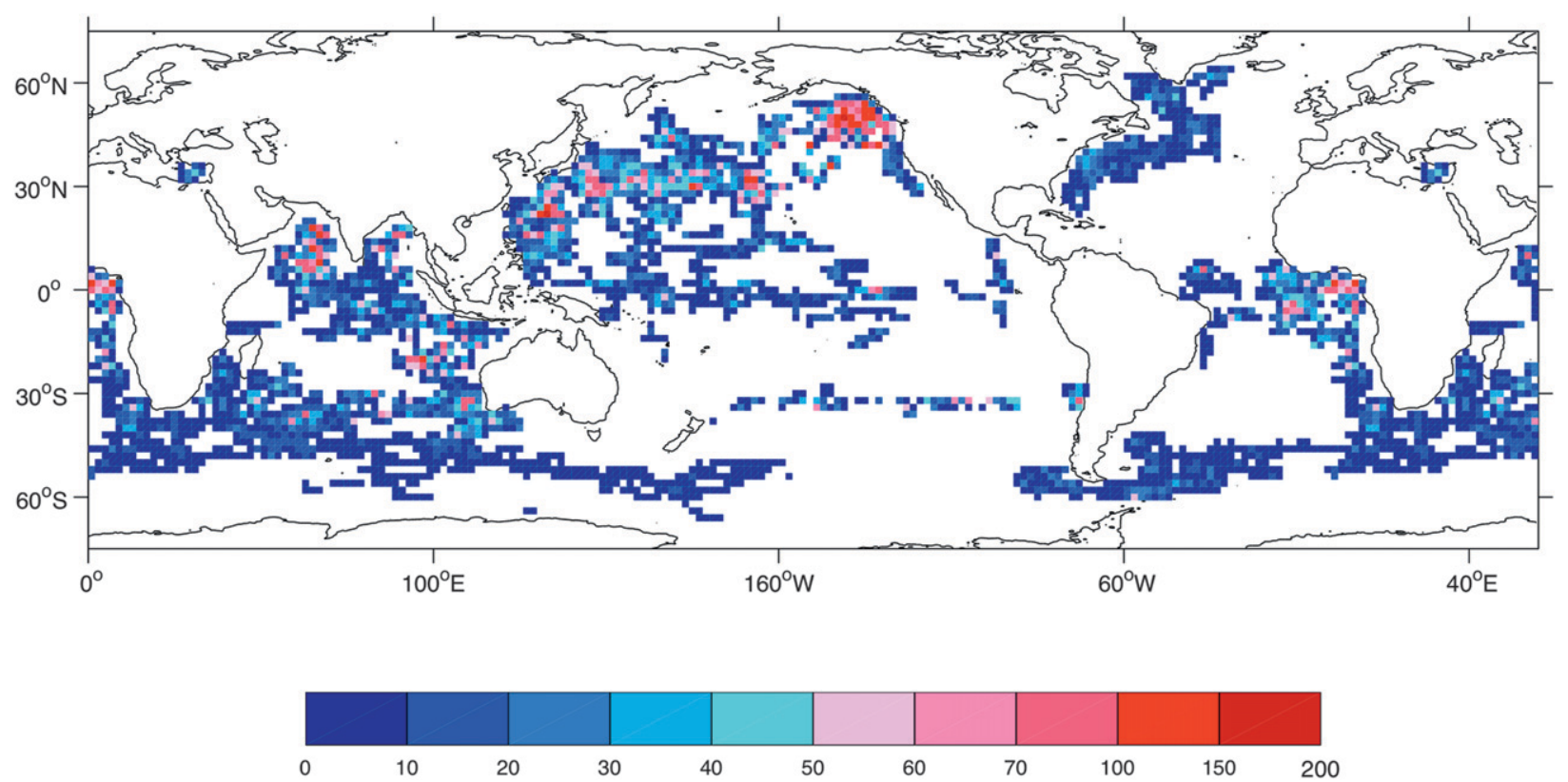

FIG. 25. ANDRO world displacement atlas for the (1850, 2050)-dbar layer. This constitutes $8.6 \%$ of the ANDRO data. 


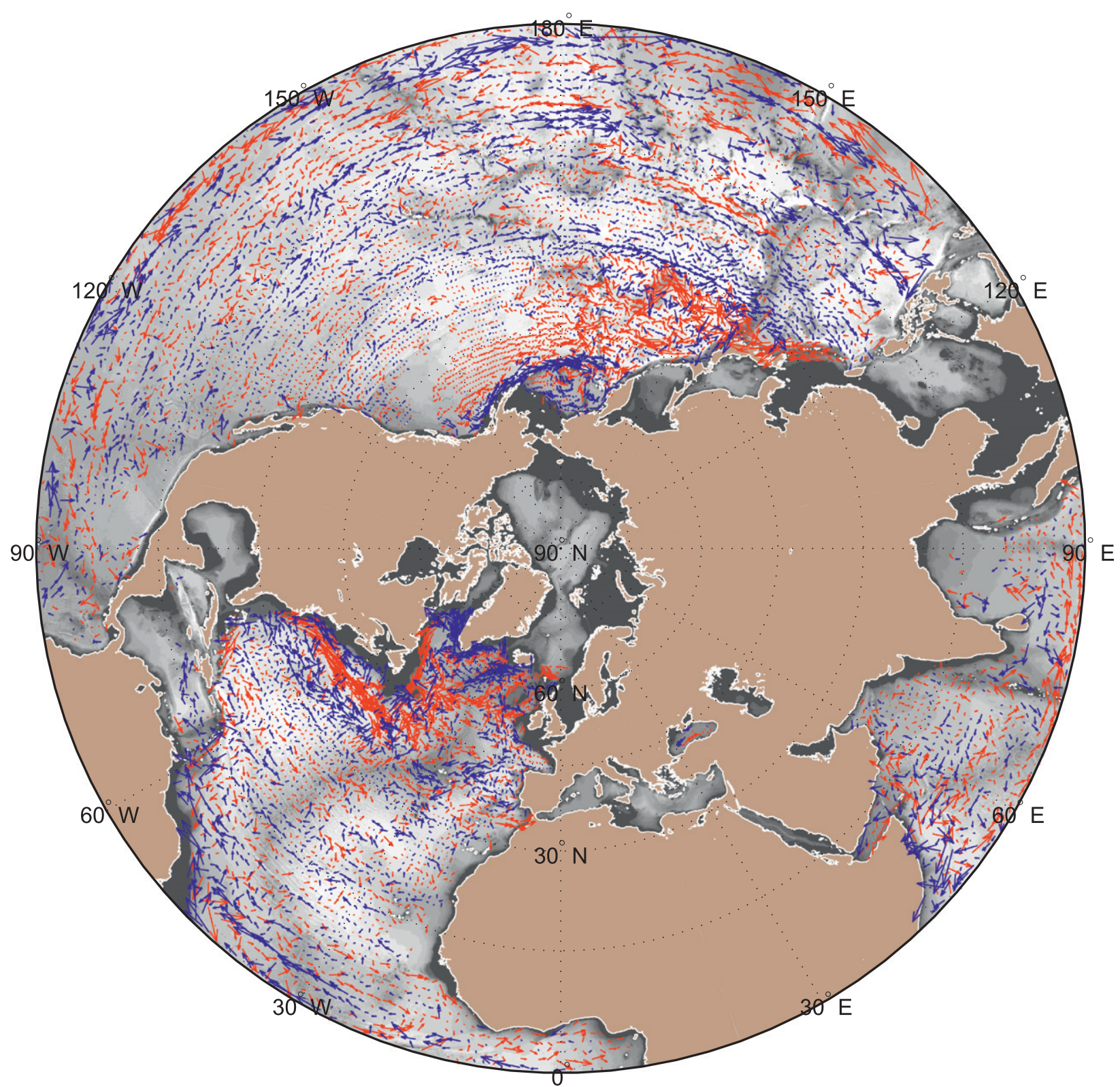

FIG. 26. Deep displacements over 60 days near 1000 dbar and for the Northern Hemisphere. Eastward flow is red, westward blue.

in ANDRO, over the period from September 1995 to December 2009. Table 2 gives, within the five layers selected, the number of displacements common to both atlases (88\%), in ANDRO only (4.5\%), in YoMaHa'07 only $(\sim 3 \%)$, and those in YoMaHa'07 that are possibly not in the good layers (7\%) assuming that ANDRO parking depths are correct.

This approach may be slightly misleading though since a float found in a given layer may not be far from the true parking depth belonging to another layer. However, a look at Fig. 13 is reassuring since the layer limits are found at depths almost devoid of displacements.
Actually, almost $10 \%$ of the YoMaHa'07 displacements have parking depths differing by more than $100 \mathrm{dbar}$ from the ANDRO ones. Figure 28 illustrates this for the North Atlantic and for the $(1250,1750)$-dbar layer.

Since grounded cycles are excluded from ANDRO, this comes from erroneous parking depths in the metafiles or from floats that do not stabilize at their nominal parking depths. Actually, assuming perfectly filled metafiles, there would still be $\sim 5 \%$ of the displacements with depths differing by more than 100 dbar from the ANDRO examples, in any atlas based on metafile data. 


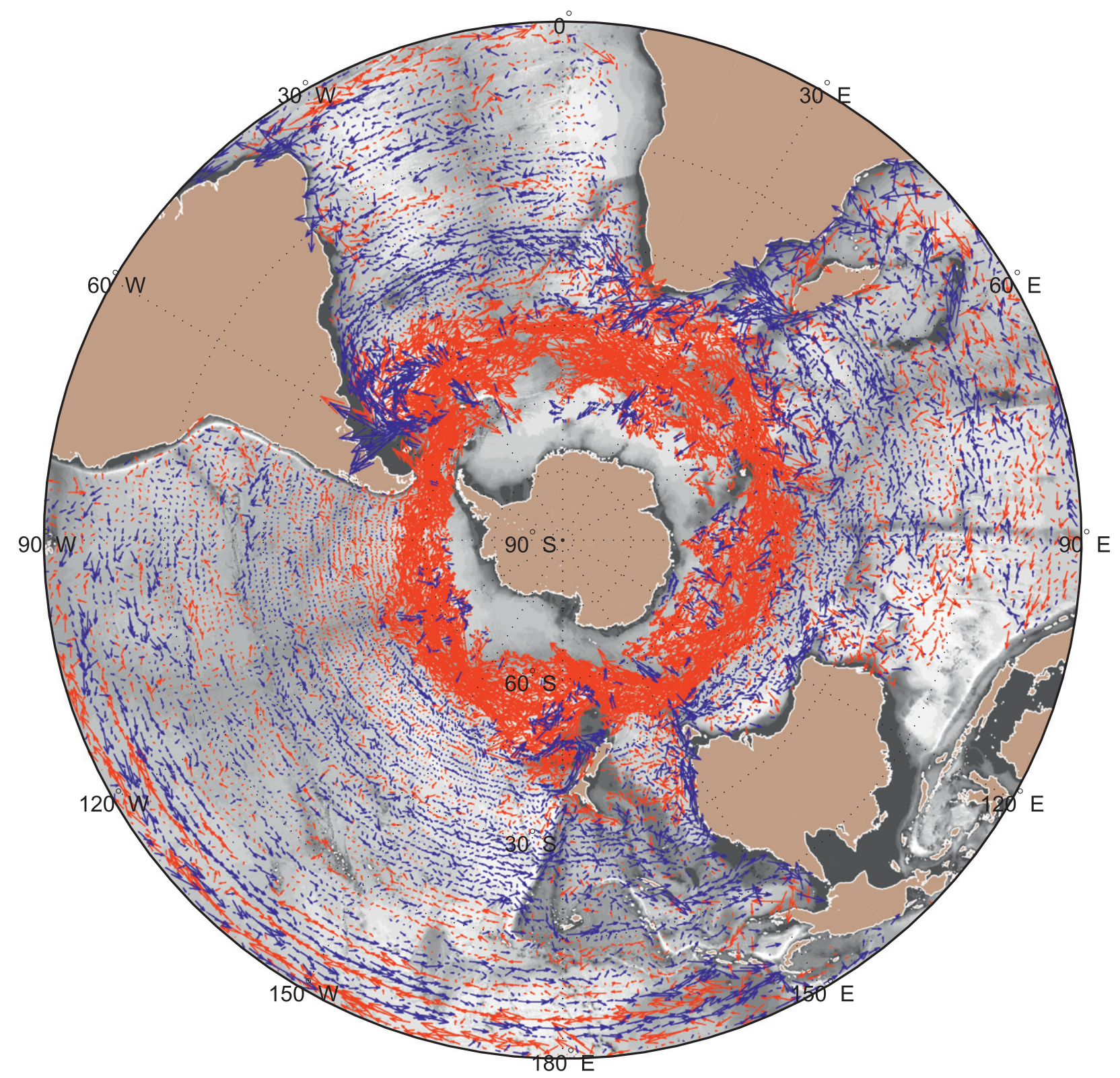

FIG. 27. Deep displacements over 60 days near 1000 dbar and for the Southern Hemisphere. Eastward flow is red, westward blue.

\section{Possible improvements}

Actual deep displacement estimation relies only on surface locations. However, contrary to GPS locations, Argos positions are not (generally) available when the floats do surface (or dive), slightly later (or sooner), implying possibly a few kilometer error on the deep displacement estimated (on average there is a delay of $1-2 \mathrm{~h})$.

To estimate the true surfacing or diving positions, one needs to determine first the corresponding times and to, then, extrapolate the surface float trajectory (sampled by the Argos locations) at these times.

For most of the floats, the surfacing time can be precisely estimated (within a few minutes), contrary to the diving time, for which one can use the envelope method proposed by Park et al. (2005) for APEX. We have presently estimated these times for APEX floats only (for PROVORs, these times are provided by the instruments themselves).

The extrapolation can be done, for example, by fitting a uniform velocity and a circular inertial motion to the 
TABLE 2. ANDRO and YoMaHa'07 comparison (number of displacements).

\begin{tabular}{|c|c|c|c|c|c|c|}
\hline Parking pressure (dbar) & In ANDRO & In YoMaHa & Common & In ANDRO only & In YoMaHa only & $\begin{array}{l}\text { Depth errors } \\
\text { in YoMaHa }\end{array}$ \\
\hline $0 \leq P \leq 250$ & 16012 & 6928 & 5089 & 1450 & 106 & 1733 \\
\hline $250<P \leq 750$ & 35956 & 20376 & 17772 & 9379 & 1452 & 1152 \\
\hline $750<P \leq 1250$ & 364401 & 378900 & 351108 & 7949 & 9522 & 18270 \\
\hline $1250<P \leq 1750$ & 61243 & 62373 & 54701 & 1680 & 1583 & 6089 \\
\hline $1750<P \leq 2250$ & 48920 & 53789 & 44079 & 2047 & 2505 & 7205 \\
\hline $2250<P$ & 82 & 0 & 0 & 0 & 0 & 0 \\
\hline Unknown & 8855 & 3995 & 114 & 1824 & 53 & 3828 \\
\hline Total & 535469 & 526361 & 472863 & 24329 & 15521 & 38277 \\
\hline
\end{tabular}

Argos fixes (Park et al. 2004). We have tested this method on 750 floats, but with only limited success (consequently, those estimates have not been saved in the DEP files yet).

Figure 29 gives an example of such an extrapolation (with a good fit), showing a large distance $(13 \mathrm{~km})$ between surfacing and the first Argos fix. Fortunately, this is not representative of the general case: our study with 750 floats gives an average delay (after surfacing or before diving) of $80 \pm 60 \mathrm{~min}$, implying an average $1.5 \pm 1.5 \mathrm{~km}$ error.

Presently, the error due to the vertical shear of the horizontal current between the surface and parking pressure is estimated using a constant shear and a constant

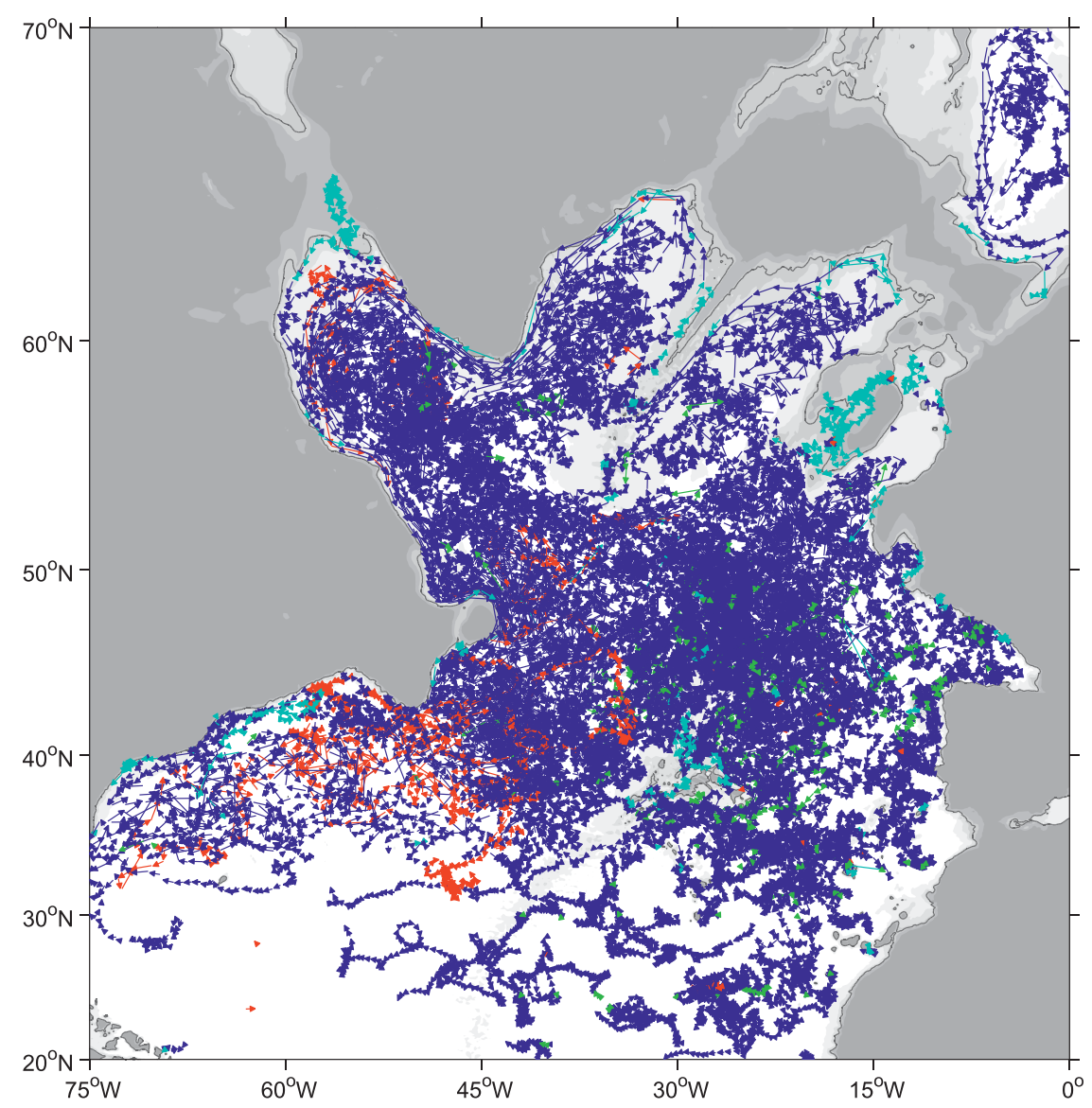

FIG. 28. The 20650 displacements found both in ANDRO and YoMaHa (with park pressures differing by $<100$ dbar) in blue. YoMaHa displacements whose park pressures differ by $>100$ dbar from the ANDRO ones are red (860 displacements). Displacements found in ANDRO only are green, and those in YoMaHa only are set in cyan (611 and 703 displacements, respectively). 


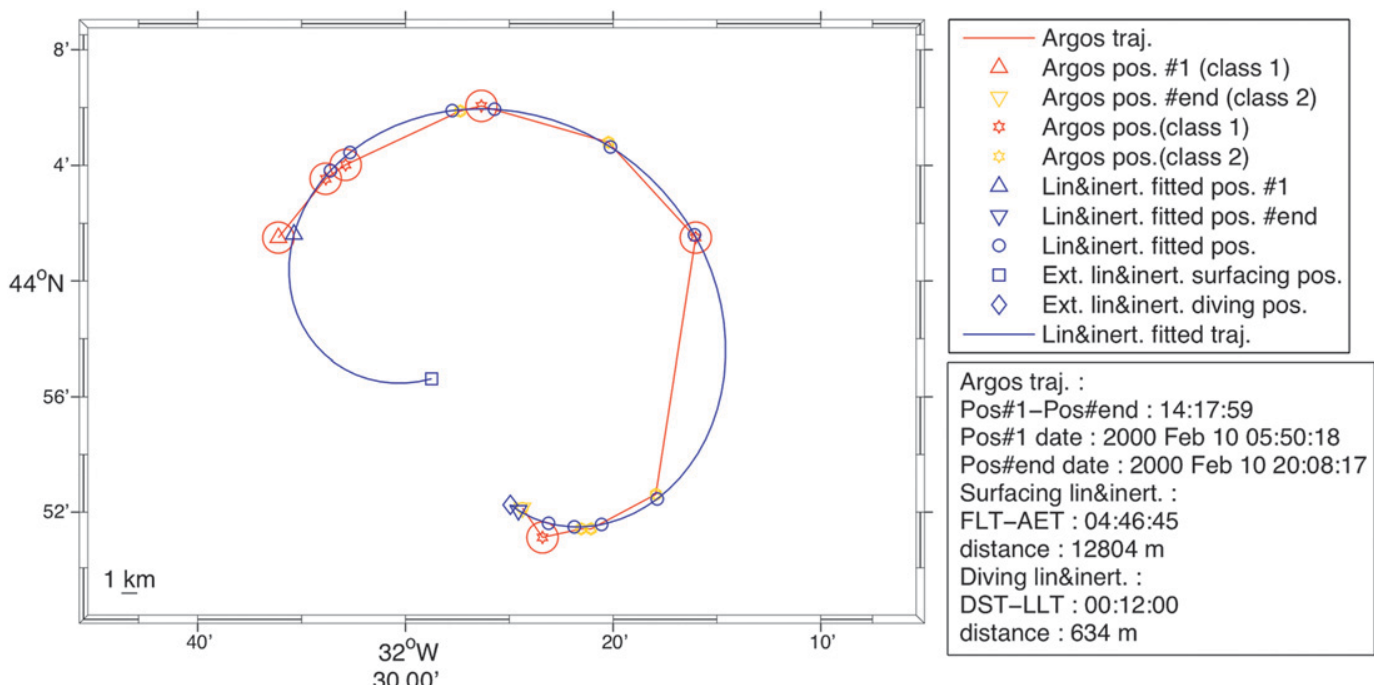

FIG. 29. Least squares fit of a uniform velocity plus a circular inertial motion on Argos fixes with extrapolated surfacing and diving positions. Dotted circles are the Argos $1 \sigma$ location uncertainty. The blue curve is the trajectory fitted to the Argos locations extrapolated at AET (open square, $\square$ ) and DST (open diamond, $\diamond$ ).

float ascent or descent rate of $10 \mathrm{~cm} \mathrm{~s}^{-1}$, following Lebedev et al. (2007). However, generally, floats do descend by steps while they ascend more or less uniformly (e.g., PROVOR takes on the order of $9 \mathrm{~h}$ to reach $1000 \mathrm{dbar}$, but only $2.5 \mathrm{~h}$ to rise from there to the surface). Knowing the precise timing of the float descent (which is now possible with most of the latest float versions), a second planned improvement will consist of estimating the horizontal motion of the float during descent and ascent. It is important to note that this "shear" correction relies on estimates of the surface velocities (see appendix A) and Iridium floats generally give only one surface fix per cycle, which prevents us from making any surface velocity estimation. It is thus desirable that for all future Iridium floats, two GPS fixes per cycle would be available.

Although the many Argos surface fixes in a given cycle are not copied in ANDRO (but only the first and last ones), they are all present in the DEP files (available on the LPO web site), which may permit the user to estimate the surface velocities along its own lines.

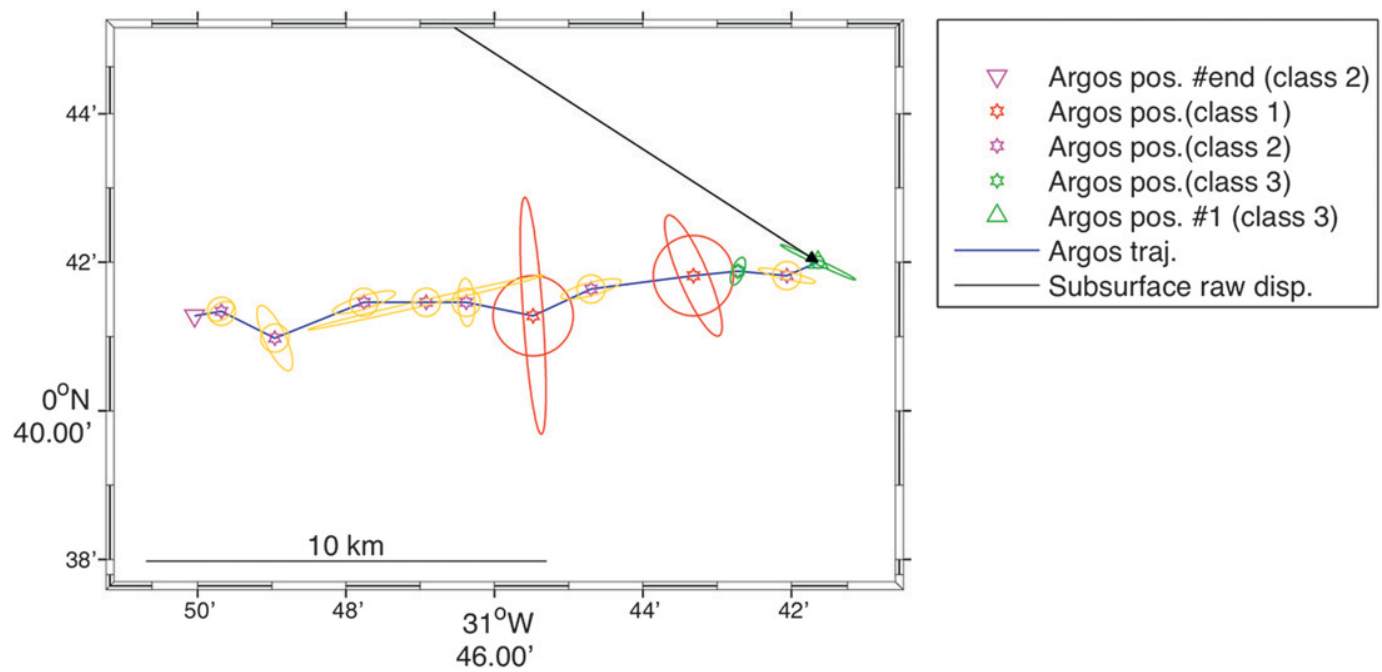

FIG. 30. Error ellipses ( 0.4 probability that on average the true location is inside the given ellipse) together with the traditional class $1-3$ error circles. 
TABLE A1. ANDRO format description.

\begin{tabular}{|c|c|c|c|}
\hline $\begin{array}{l}\text { Column } \\
\text { number }\end{array}$ & Content & $\begin{array}{l}\text { Format } \\
\text { (Matlab) }\end{array}$ & $\begin{array}{l}\text { Default } \\
\text { value }\end{array}$ \\
\hline 1 & Longitude $X_{\text {deep }}^{n}=\left(X_{\text {first }}^{n}+X_{\text {last }}^{n-1}\right) / 2$ of the location where the deep velocity is calculated & $9.4 \mathrm{f}$ & -999.9999 \\
\hline 2 & Latitude $Y_{\text {deep }}^{n}=\left(Y_{\text {first }}^{n}+Y_{\text {last }}^{n-1}\right) / 2$ of the location where the deep velocity is calculated & $8.4 \mathrm{f}$ & -99.9999 \\
\hline 3 & Representative parking pressure $p_{\text {deep }}^{n}(\mathrm{dbar})$ for this cycle & $6.1 \mathrm{f}$ & -999.9 \\
\hline 4 & Parking temperature $t_{\text {deep }}^{n}\left({ }^{\circ} \mathrm{C}\right)$ for this cycle & $7.3 \mathrm{f}$ & -99.999 \\
\hline 5 & Parking salinity $S_{\text {deep }}^{n}(\mathrm{PSU})$ for this cycle & $7.3 \mathrm{f}$ & -99.999 \\
\hline 6 & Julian time $T_{\text {deep }}^{n}$ (days) when deep velocity is estimated & $9.3 \mathrm{f}$ & -9999.999 \\
\hline 7 & $\begin{array}{l}\text { Eastward component of the deep velocity } U_{\text {deep }}^{n}\left(\mathrm{~cm} \mathrm{~s}^{-1}\right) \text { at } p_{\text {deep }}^{n} \text {, estimated as } \\
\quad\left(X_{\text {first }}^{n}-X_{\text {last }}^{n-1}\right) \times \operatorname{coef} \times \cos \left(\pi Y_{\text {deep }}^{n} / 180\right) /\left(T_{\text {first }}^{n}-T_{\text {last }}^{n-1}\right)\end{array}$ & $7.2 \mathrm{f}$ & -999.99 \\
\hline 8 & $\begin{array}{l}\text { Northward component of the deep velocity } V_{\text {deep }}^{n}\left(\mathrm{~cm} \mathrm{~s}^{-1}\right) \text { at } p_{\text {deep }}^{n} \text {, estimated as } \\
\quad\left(Y_{\text {first }}^{n}-Y_{\text {last }}^{n-1}\right) \times \operatorname{coef} /\left(T_{\text {first }}^{n}-T_{\text {last }}^{n-1}\right)\end{array}$ & $7.2 \mathrm{f}$ & -999.99 \\
\hline 9 & Error on the eastward component of the deep velocity $\varepsilon_{\mathrm{U} \text { deep }}^{n}\left(\mathrm{~cm} \mathrm{~s}^{-1}\right)$, absolute value & $7.2 \mathrm{f}$ & -999.99 \\
\hline 10 & Error on the northward component of the deep velocity $\varepsilon_{\mathrm{V} \text { deep }}^{n}\left(\mathrm{~cm} \mathrm{~s}^{-1}\right)$, absolute value & $7.2 \mathrm{f}$ & -999.99 \\
\hline 11 & $\begin{array}{l}\text { Longitude } X_{\text {surffirst }}^{n} \text { of the location where the first surface velocity is calculated (over the first } 6 \mathrm{~h} \text { at the } \\
\text { surface) }\end{array}$ & $9.4 \mathrm{f}$ & -999.9999 \\
\hline 12 & Latitude $Y_{\text {surffirst }}^{n}$ of the location where the first surface velocity is calculated & $8.4 \mathrm{f}$ & -99.9999 \\
\hline 13 & Julian time $T_{\text {surf,first }}^{n}$ (days) when first surface velocity is calculated & $9.3 \mathrm{f}$ & -9999.999 \\
\hline 14 & Eastward component of the first surface velocity $U_{\text {surf.first }}^{n}\left(\mathrm{~cm} \mathrm{~s}^{-1}\right)$ & $7.2 \mathrm{f}$ & -999.99 \\
\hline 15 & Northward component of the first surface velocity $V_{\text {surf,first }}^{n}\left(\mathrm{~cm} \mathrm{~s}^{-1}\right)$ & $7.2 \mathrm{f}$ & -999.99 \\
\hline 16 & Error on the eastward component of the first surface velocity $\varepsilon_{U \text { surf,first }}^{n}\left(\mathrm{~cm} \mathrm{~s}^{-1}\right)$, absolute value & $7.2 \mathrm{f}$ & -999.99 \\
\hline 17 & Error on the northward component of the first surface velocity $\varepsilon_{V \text { surf,first }}^{n}\left(\mathrm{~cm} \mathrm{~s}^{-1}\right)$, absolute value & $7.2 \mathrm{f}$ & -999.99 \\
\hline 18 & $\begin{array}{l}\text { Longitude } X_{\text {surf,last }}^{n} \text { of the location where the last surface velocity is calculated (over the last } 6 \mathrm{~h} \text { at the } \\
\text { surface) }\end{array}$ & $9.4 \mathrm{f}$ & -999.9999 \\
\hline 19 & Latitude $Y_{\text {surf,last }}^{n}$ of the location where the last surface velocity is calculated & $8.4 \mathrm{f}$ & -99.9999 \\
\hline 20 & Julian time $T_{\text {surf,last }}^{n}$ (days) when the last surface velocity is calculated & $9.3 \mathrm{f}$ & -9999.999 \\
\hline 21 & Eastward component of last surface velocity $U_{\text {surf,last }}^{n}\left(\mathrm{~cm} \mathrm{~s}^{-1}\right)$ & $7.2 \mathrm{f}$ & -999.99 \\
\hline 22 & Northward component of last surface velocity $V_{\text {surf, last }}^{n}\left(\mathrm{~cm} \mathrm{~s}^{-1}\right)$ & $7.2 \mathrm{f}$ & -999.99 \\
\hline 23 & Error on the eastward component of the last surface velocity $\varepsilon_{U \text { surf }}^{n}$ & $7.2 \mathrm{f}$ & -999.99 \\
\hline 24 & Error on the northward component of the last surface velocity $\varepsilon_{V \text { surf,last }}^{n}\left(\mathrm{~cm} \mathrm{~s}^{-1}\right)$, absolute value & $7.2 \mathrm{f}$ & -999.99 \\
\hline 25 & Longitude of the last fix at the sea surface during the previous cycle $X_{\text {last }}^{n-1}$ & $9.4 \mathrm{f}$ & -999.9999 \\
\hline 26 & Latitude of the last fix at the sea surface during the previous cycle $Y_{\text {last }}^{n-1}$ & $8.4 \mathrm{f}$ & -99.9999 \\
\hline 27 & Julian time of the last fix at the sea surface during the previous cycle $T_{\text {last }}^{n-1}$ & $9.3 \mathrm{f}$ & -9999.999 \\
\hline 28 & Longitude of the first fix at the sea surface during the current cycle $X_{\text {first }}^{n}$ & $9.4 \mathrm{f}$ & -999.9999 \\
\hline 29 & Latitude of the first fix at the sea surface during the current cycle $Y_{\text {first }}^{n}$ & $8.4 \mathrm{f}$ & -99.9999 \\
\hline 30 & Julian time of the first fix at the sea surface during the current cycle $T_{\text {first }}^{n}$ & $9.3 \mathrm{f}$ & -9999.999 \\
\hline 31 & Longitude of the last fix at the sea surface during the current cycle $X_{\text {last }}^{n}$ & $9.4 \mathrm{f}$ & -999.9999 \\
\hline 32 & Latitude of the last fix at the sea surface during the current cycle $Y_{\text {last }}^{n}$ & $8.4 \mathrm{f}$ & -99.9999 \\
\hline 33 & Julian time of the last fix at the sea surface during the current cycle $T_{\text {last }}^{n}$ & $9.3 \mathrm{f}$ & -9999.999 \\
\hline 34 & Number of surface fixes $N_{\text {fix }}^{n}$ during the current cycle & $5 d$ & - \\
\hline 35 & Float WMO number & $7 d$ & - \\
\hline 36 & Cycle number & $3 d$ & - \\
\hline 37 & Profile number as given in the NetCDF prof file & $3 \mathrm{~d}$ & -99 \\
\hline
\end{tabular}

In appendix A, a better estimate of the deep velocity (at the parking depth) is given, showing the value of both the surface extrapolation and the vertical shear bias correction. Such an improvement is feasible from the detailed DEP data.

It would also be rewarding to consider the error ellipses on the Argos locations (instead of the approximate 1- $\sigma$ Argos error circles obtained from the location classes) for a better fit of the float surface trajectories since, as shown in Fig. 30, location error can be quite large even for a class 3 Argos fix. Ellipses have only been available since 2009, but efforts are under way by CLS to provide them for older locations.

\section{Conclusions}

Almost all ANDRO atlas displacement depths are in situ measured values. YoМаHa'07 displacement depths are only copied from the nominal parking depths found in the meta.nc files, implying erroneous drifting depths for almost $10 \%$ of the displacements (because of erroneous nominal parking depth proper and because floats did not stabilize at their programmed parking depth or were on board a ship). Thus, even with perfectly filled metafiles, $5 \%$ erroneous depths would remain as compared to ANDRO.

Thanks to the Argos and Iridium raw data provided by the DACs, we have been able to eliminate decoding errors 


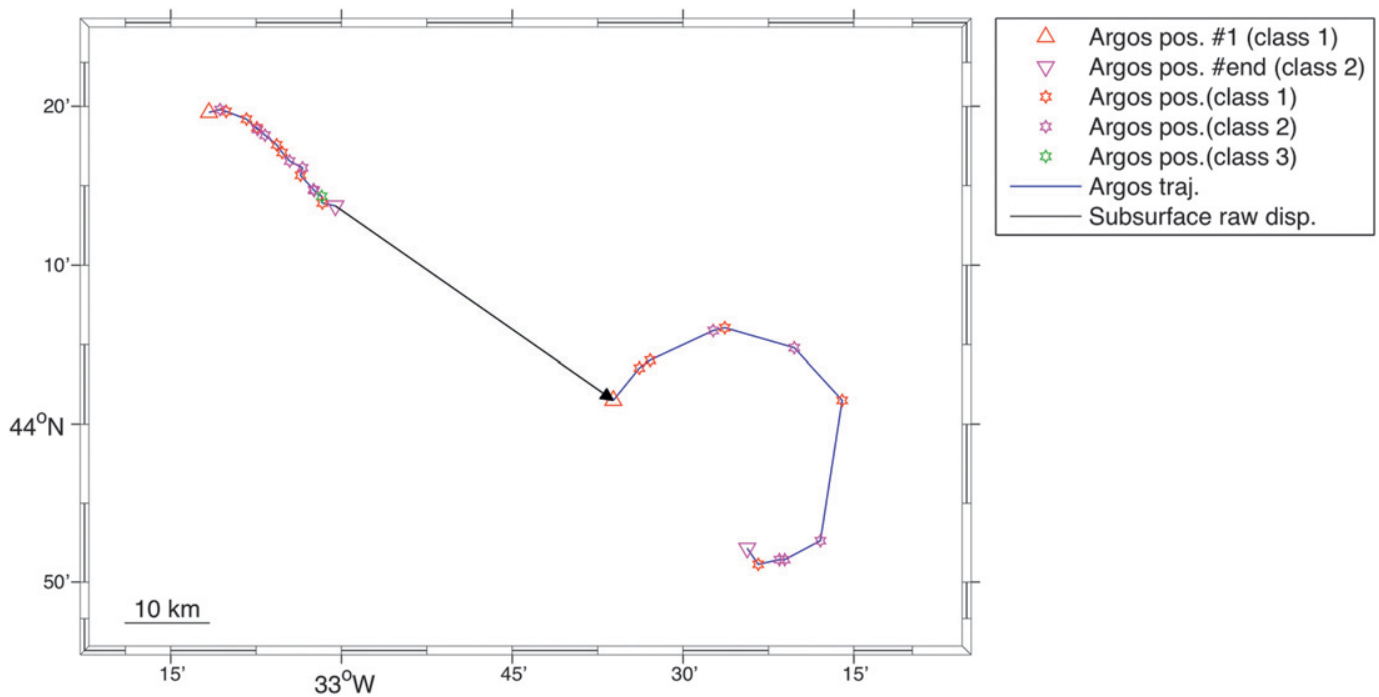

FIG. A1. WMO float 69027 surface trajectories at cycles 8 and 9, with the ANDRO-estimated deep displacement (at 1500 dbar) during cycle 9 (cycle duration is 15 days and the time interval between the last location at cycle 8 and the first location at cycle 9 is 14.406 days).

and to concentrate on the float functioning proper. Furthermore, we have slightly enlarged the Argo dataset with cycles not publicly available (for reasons unknown to us).

Meanwhile, the DACs are progressively updating their NetCDF data files, as a result of our work. Since the YoMaHa'07 atlas is regenerated periodically, the differences (in parking depth) between ANDRO and YoMaHa'07 will tend progressively toward 5\%.

The ANDRO atlas (updated 29 November 2012) contains all the world Argo data (until 1 January 2010) from the AOML, Coriolis, JMA, CSIRO, BODC, MEDS, INCOIS, KORDI, KMA, and CSIO DACs.

The ANDRO atlas (and its future updates) is freely available on the Coriolis or LPO web sites.

Acknowledgments. The authors wish to thank Claudia Schmid and Elizabeth Forteza (AOML), Taiyo Kobayashi (JAMSTEC), Mizuho Hoshimoto (JMA), Ann Thresher (CSIRO), Udaya Bhaskar (INCOIS), Mathieu Ouellet and Anh Tran (MEDS), Justin Buck and Sam Jones (BODC), Pil-Hun Chang (KMA), Liu Zenghong (CSIO), Moon-Sik Suk (KORDI), and Thierry Carval and Vincent Bernard (Coriolis) for sharing their data and cooperating strongly with us. We owe much to John Gilson (SIO), Breck Owens (WHOI), and Serge Le Reste (IFREMER) who introduced us to the SIO SOLO, WHOI SOLO, and PROVOR subtleties. Brian King's (NOCS) support was helpful in convincing IFREMER to support this study, following an initial suggestion from Pierre-Yves Le Traon (Ifremer). Last but not least, we could not conclude without thinking of our passed colleague Gérard Loaëc, who was the main designer of the PROVOR float: this study is a tribute to his memory.

\section{APPENDIX A}

\section{ANDRO Format and Velocity Errors}

ASCII ANDRO file (one line for one cycle) has 37 columns whose contents are described in Table A1 (based on the YoMaHa'05 format).

Julian time (days) corresponds to the number of days elapsed since 0000 UTC 1 January 2000. Adding 18262.000 will convert it into the Julian time used by Argos (relative to 0000 UTC 1 January 1950).

Surface velocities and corresponding errors are estimated as in Lebedev et al. (2007), using a linear least squares regression: if $T_{i}$ and $Y_{i}(i=1, \ldots, N)$ are the times and latitudes of the surface fixes for the current cycle, $\hat{V}_{\text {surf }}=\sum\left(Y_{i}-\bar{Y}\right)\left(T_{i}-\bar{T}\right) / \sum\left(T_{i}-\bar{T}\right)^{2}$, where $\bar{T}$ and $\bar{Y}$ denote the mean of the $T_{i}$ and $Y_{i}$. Under a Gaussian distribution assumption, the error $\varepsilon_{V}$ on $\hat{V}_{\text {surf }}$ is given by $\varepsilon_{V}^{2}=\sum\left[Y_{i}-\bar{Y}-\hat{V}_{\text {surf }}\left(T_{i}-\bar{T}\right)\right]^{2} /(N-2) \sum\left(T_{i}-\bar{T}\right)^{2}$ (and similar expressions for $\hat{U}_{\text {surf }}$ and $\varepsilon_{U}^{2}$ ). Clearly, these estimates may not be adequate where inertial motions are important and the time span of the surface fixes is comparable to the inertial period. In that case, one should use instead a least squares fit of a uniform current and a circular inertial motion as proposed by Park et al. (2004). An example of such a fit is given in section 5 . 


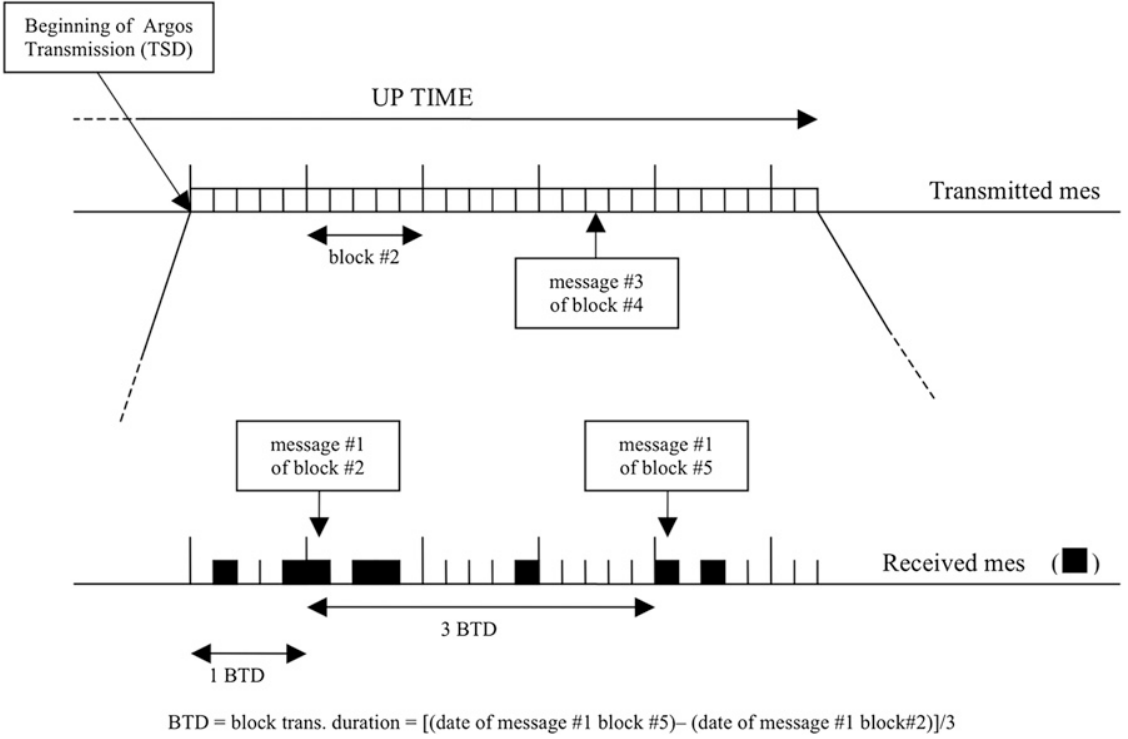

FIG. B1. The preferred method for determining the TSD.

The deep velocity components $u_{\text {deep }}$ and $v_{\text {deep }}$ are estimated (in cm s $\left.{ }^{-1}\right)$, respectively, as $\hat{U}_{\text {deep }}^{n}=\left(X_{\text {first }}^{n}-X_{\text {last }}^{n-1}\right) \times$ $\operatorname{coef} \times \cos \left(\pi Y_{\text {deep }}^{n} / 180\right) / \Delta T$ and $\hat{V}_{\text {deep }}^{n}=\left(Y_{\text {first }}^{n}-Y_{\text {last }}^{n-1}\right) \times$ $\operatorname{coef} / \Delta T$, where $\Delta T=T_{\text {first }}^{n}-T_{\text {last }}^{n-1}$ ( $T_{\text {first }}^{n}$ is the time of the first fix at the sea surface during the current cycle and $T_{\text {last }}^{n-1}$ is the time of the last fix at the sea surface during the previous cycle) and coef $=1852 \times 60 / 864$ since latitudes $Y_{i}$ are given in degrees and times in days. Lebedev et al. (2007) give an estimate of the error on the deep velocity due to the vertical shear between the surface and the parking pressure during the float's descents or ascents. The assumptions made are that the shear is constant in the vertical and the rates of descent and ascent are also constant $\left(W=0.1 \mathrm{~m} \mathrm{~s}^{-1}\right)$. Neglecting the time differences between $T_{\text {last }}^{n-1}$ and descent start time (DST) and the difference between ascent end time (AET) and $T_{\text {first }}^{n}$, one obtains $\hat{U}_{\text {deep }}^{n}-u_{\text {deep }}^{n}=\alpha(1-\alpha)^{-1}\left(\hat{U}_{\text {surf,last }}^{n-1}+\right.$ $\left.\hat{U}_{\text {surf,first }}^{n}-2 \hat{U}_{\text {deep }}^{n}\right) / 2$ with $\alpha=\mathrm{PD} \times W^{-1} \times \Delta T^{-1}$, and a similar expression for $\hat{V}_{\text {deep }}^{n}-v_{\text {deep }}^{n}$. PD is the parking depth in meters and $\Delta T$ is in seconds. However, in general and for Argos floats, the two previous time differences are not at all negligible since on average (see section 5) they are of the order of $1 \mathrm{~h}$ (whence a 2-km displacement with a $0.5 \mathrm{~m} \mathrm{~s}^{-1}$ surface current) and comparable

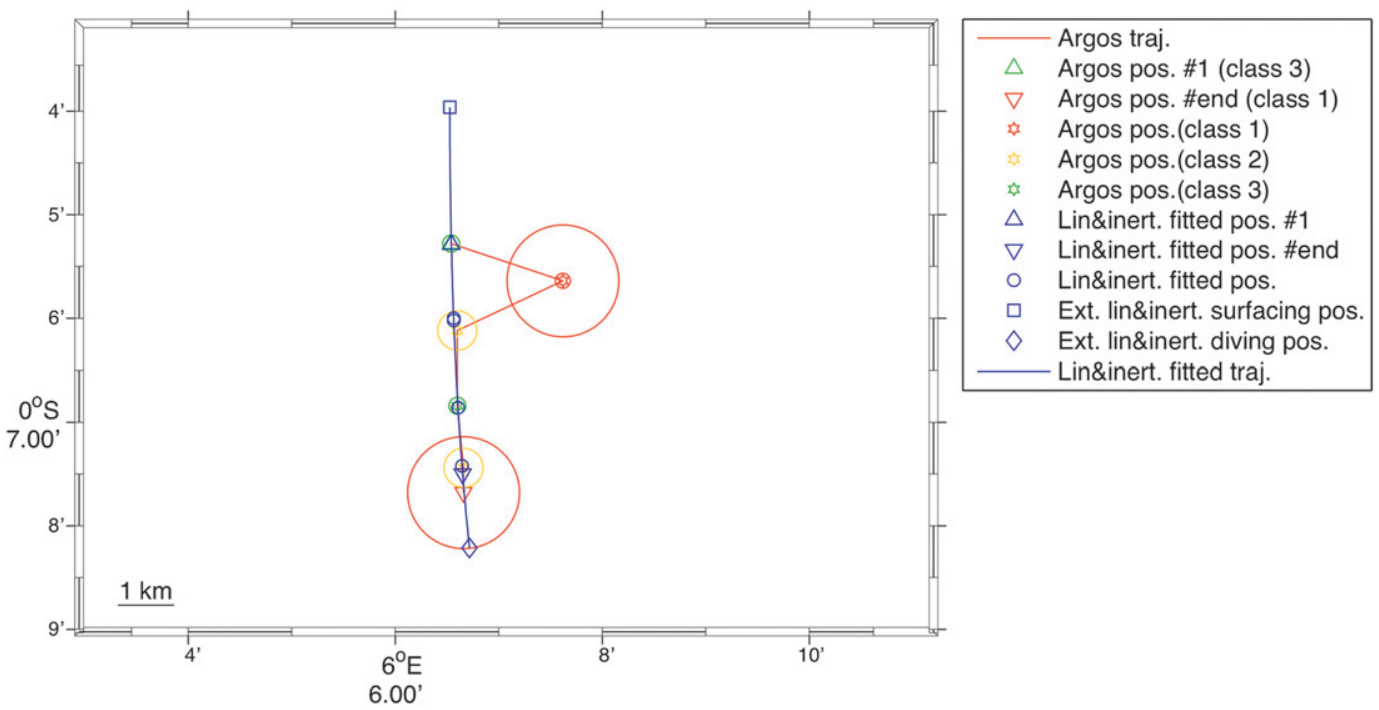

FIG. C1. Surface trajectory for WMO float 1900601 at cycle 40. The blue curve is the trajectory fitted to the Argos locations, extrapolated at AET (open square, $\square$ ) and DST (open diamond, $\diamond$ ). 


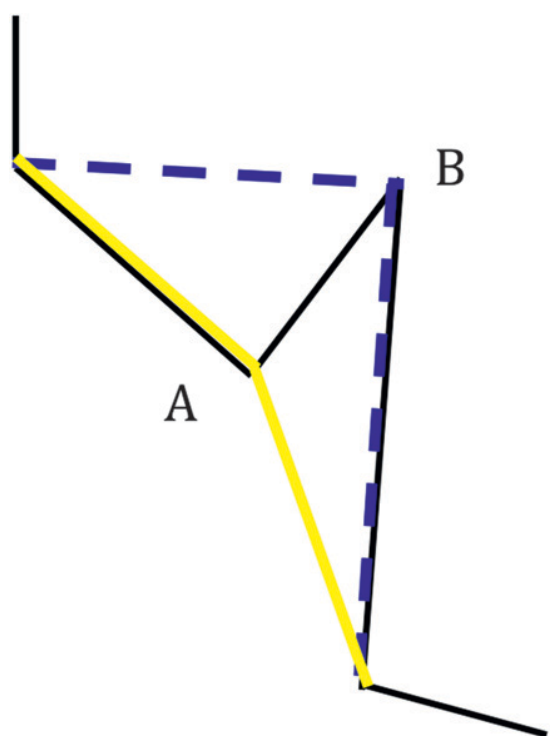

FIG. C2. The segment AB is questionable. The positions before and after are good. One selects the trajectory (yellow or blue) that gives the minimum average speed. The position $A$ or $B$ not belonging to the selected trajectory is flagged as bad.

to the displacement induced by the current shear in the vertical $\left(2.5 \mathrm{~km}\right.$ with a shear of $0.5 \mathrm{~m} \mathrm{~s}^{-1}$ over $\left.1000 \mathrm{~m}\right)$. Furthermore, the surface current may change direction while the float is at the surface and what is needed are the surface velocities just before diving and just after surfacing. Our linearly estimated $\hat{U}_{\text {surf,last }}^{n-1}$ and $\hat{U}_{\text {surffirst }}^{n}$ values may be grossly in error. With Iridium floats, only one fix is generally available, preventing any surface velocity estimation. With two or three GPS fixes available (which happens occasionally if an upload failure occurs), this cause of error would be less problematic since the surface phase would last on the order of $1 \mathrm{~h}$ at most (this pleads for at least two GPS locations at the surface for future floats). The error estimates given in the present version of ANDRO are to be used with caution and are probably underestimated, as shown below with a specific example.

Figure A1 shows the 1500-dbar displacement for float WMO 69027 at cycle 9, as it is estimated in ANDRO (i.e., from the last surface location at cycle 8 to the first surface location at cycle 9). The corresponding time interval is 14.406 days (cycles are exactly 15 days long).

Figure 29 shows the error circles and the surface fitted trajectory at cycle 9, together with the extrapolated positions at AET and DST. There is a $4 \mathrm{~h} 46 \min 45 \mathrm{~s}$ (or 0.199 days) delay between AET and FLT. Ascent end location extrapolated at AET is $43.944^{\circ} \mathrm{N}, 32.479^{\circ} \mathrm{W}$, while the first surface location (FL) is $44.025^{\circ} \mathrm{N}, 32.602^{\circ} \mathrm{W}$.
TABLE D1. DEP format description.

\begin{tabular}{|c|c|c|c|}
\hline $\begin{array}{l}\text { Column } \\
\text { No. }\end{array}$ & Contents & $\begin{array}{l}\text { Format } \\
\text { (Matlab) }\end{array}$ & Default value \\
\hline 1 & Float WMO No. & $7 d$ & \\
\hline 2 & Cycle No. & $3 d$ & \\
\hline 3 & Information type & $2 d$ & \\
\hline 4 & Julian (1950) date & $14.8 \mathrm{f}$ & 99999.99999999 \\
\hline 5 & Date flag & $2 d$ & 99 \\
\hline 6 & Gregorian date & $\begin{array}{l}\text { yyyy/mm/dd } \\
\text { HH:MM:SS }\end{array}$ & $\begin{array}{c}\text { 9999/99/99 } \\
\text { 99:99:99 }\end{array}$ \\
\hline 7 & Ordering No. & $05 \mathrm{~d}$ & \\
\hline 8 & Lon & $8.3 \mathrm{f}$ & -999.999 \\
\hline 9 & Lat & $7.3 \mathrm{f}$ & -99.999 \\
\hline 10 & Position flag & $2 \mathrm{~d}$ & 99 \\
\hline 11 & Location class & $\mathrm{c}$ & '9' \\
\hline 12 & Satellite ID & $\mathrm{c}$ & '9' \\
\hline 13 & Pressure & $6.1 \mathrm{f}$ & 9999.9 \\
\hline 14 & Pressure flag & $3 d$ & 999 \\
\hline 15 & Temp & $6.3 f$ & 99.999 \\
\hline 16 & Temp flag & $3 d$ & 999 \\
\hline 17 & Salinity & $6.3 \mathrm{f}$ & 99.999 \\
\hline 18 & Salinity flag & $3 d$ & 999 \\
\hline 19 & Grounded flag & $02 d$ & 00 \\
\hline 20 & Data origin or state & $2 d$ & 99 \\
\hline 21 & $\begin{array}{l}\text { Gregorian date of } \\
\text { last update }\end{array}$ & yyyy $/ \mathrm{mm} / \mathrm{dd}$ & \\
\hline 22 & $\begin{array}{l}\text { Profile No. as } \\
\text { given in NetCDF } \\
\text { prof file }\end{array}$ & $3 d$ & -1 \\
\hline
\end{tabular}

The last surface Location (LL) at cycle 8 is $44.229^{\circ} \mathrm{N}, 33.009 \mathrm{~W}$, while the descent start location extrapolated at DST ( $877 \mathrm{~s}$ later) is $44.237^{\circ} \mathrm{N}, 33.007^{\circ} \mathrm{W}$. Thus, the time interval between DST and AET is $14.406-$ $0.199-0.010=14.197$ days. Using the extrapolated positions given above, one finds a new (and hopefully better) estimation for the average deep velocity: $\tilde{U}_{\text {deep }}^{9}=3.44 \mathrm{~cm} \mathrm{~s}^{-1}$ and $\tilde{V}_{\text {deep }}^{9}=-2.65 \mathrm{~cm} \mathrm{~s}^{-1}$ (the ANDRO estimates are $\hat{U}_{\text {deep }}^{9}=2.62 \mathrm{~cm} \mathrm{~s}^{-1}$ and $\hat{V}_{\text {deep }}^{9}=$ $-1.82 \mathrm{~cm} \mathrm{~s}^{-1}$ ).

Following on the example of float 69027 , we now consider the current shear during the descent and ascent. The surface velocities given in ANDRO (estimated as explained before) are $\mathbf{U}_{\text {surf,last }}^{8}=(18.8$,

TABLE D2. Specific values for "cycle number" (column 2).

\begin{tabular}{cl}
\hline \hline Cycle No. & \multicolumn{1}{c}{ Meaning } \\
\hline-1 & Float launch position \\
0 & For APEX and ARVOR floats, surface \\
& drift prior to the first dive \\
& For PROVOR floats, first cycle \\
& For other floats, unused \\
999 & End of life (EOL) cycle \\
\hline
\end{tabular}


TABLE D3. Meaning of "information type" codes (column 3).

\begin{tabular}{|c|c|}
\hline $\begin{array}{l}\text { Information } \\
\text { type code }\end{array}$ & Meaning \\
\hline 0 & Launch \\
\hline 1 & $\begin{array}{l}\text { Surface pressure measurement (done just before } \\
\text { descent start) }\end{array}$ \\
\hline 2 & $\begin{array}{l}\text { Pressure offset (used to correct APEX pressure } \\
\text { measurements) }\end{array}$ \\
\hline 3 & $\begin{array}{l}\text { End of Argos transmission and start of buoyancy } \\
\text { reduction (TET) }\end{array}$ \\
\hline 4 & $\begin{array}{l}\text { Surface pressure measurement (done just after } \\
\text { ascent end) }\end{array}$ \\
\hline 5 & \\
\hline 6 & Descent start to parking depth (DST) \\
\hline 7 & $\begin{array}{l}\text { First stabilization during descent to parking depth } \\
\text { (FST) }\end{array}$ \\
\hline 8 & $\begin{array}{l}\text { Descending profile measurement (and all } \\
\text { measurements done during descent to parking } \\
\text { depth) }\end{array}$ \\
\hline 9 & $\begin{array}{l}\text { Maximum pressure measured before stabilization } \\
\text { at parking depth }\end{array}$ \\
\hline 10 & $\begin{array}{l}\text { Measurements done at the end of the stabilization } \\
\text { phase at parking depth }\end{array}$ \\
\hline 11 & Descent end (DET) \\
\hline 12 & $\begin{array}{l}\text { Measurement done during the drifting phase at } \\
\text { depth }\end{array}$ \\
\hline 13 & $\begin{array}{l}\text { Minimal pressure measured by the float during } \\
\text { the drifting phase at depth }\end{array}$ \\
\hline 14 & $\begin{array}{l}\text { Maximal pressure measured by the float during } \\
\text { the drifting phase at depth }\end{array}$ \\
\hline 15 & $\begin{array}{l}\text { Measurement done at the end of the drifting } \\
\text { phase at depth }\end{array}$ \\
\hline 16 & $\begin{array}{l}\text { Mean of the measurements done during the } \\
\text { drifting phase at depth }\end{array}$ \\
\hline 17 & $\begin{array}{l}\text { Median value of the measurements done during } \\
\text { the drifting phase at depth }\end{array}$ \\
\hline \multicolumn{2}{|l|}{18} \\
\hline \multicolumn{2}{|l|}{19} \\
\hline 20 & Reference depth of the displacement (RPP) \\
\hline 21 & Descent start to profile pressure (DDST) \\
\hline 22 & $\begin{array}{l}\text { Maximum pressure measured before stabilization } \\
\text { at profile depth }\end{array}$ \\
\hline 23 & Descent end at profile depth (DDET) \\
\hline 24 & Measurement done just before profile start \\
\hline \multicolumn{2}{|l|}{25} \\
\hline 26 & $\begin{array}{l}\text { Ascent start, computed-estimated using float } \\
\text { technical information (AST) }\end{array}$ \\
\hline 27 & $\begin{array}{l}\text { Ascent start extrapolated from dated ascending } \\
\text { profile measurements }\end{array}$ \\
\hline 28 & $\begin{array}{l}\text { Ascending profile measurement (and all } \\
\text { measurements done during ascent to surface) }\end{array}$ \\
\hline 29 & Time at $100 \mathrm{dbar}$ during ascent (for $N E M O$ ) \\
\hline \multicolumn{2}{|l|}{30} \\
\hline 31 & $\begin{array}{l}\text { Ascent end computed-estimated using float } \\
\text { technical information (AET) }\end{array}$ \\
\hline 32 & $\begin{array}{l}\text { Ascent end extrapolated from dated ascending } \\
\text { profile measurements }\end{array}$ \\
\hline 33 & Transmission start (TST) \\
\hline \multicolumn{2}{|r|}{ 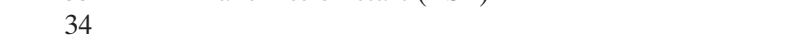 } \\
\hline 35 & First Argos message reception (FMT) \\
\hline 36 & Argos location \\
\hline
\end{tabular}

TABLE D3. (Continued)

\begin{tabular}{cc}
\hline \hline $\begin{array}{c}\text { Information } \\
\text { type code }\end{array}$ & Meaning \\
\hline 37 & Surface measurement \\
38 & Last Argos message reception (LMT) \\
39 & Transmission end and start of buoyancy reduction \\
40 & (TET, identical to "3" for two consecutive cycles) \\
& \\
$\ldots$ & Estimated surface positions \\
46 & Spy measurements done during descent to park \\
51 & (PROVOR Iridium) \\
52 & Spy measurements done during descent from park \\
& to profile (PROVOR Iridium) \\
53 & Spy measurements done during ascent to surface \\
& (PROVOR Iridium) \\
\end{tabular}

-18.1) $\mathrm{cm} \mathrm{s}^{-1}$ and $\mathbf{U}_{\text {surffirst }}^{9}=(107.4,34.0) \mathrm{cm} \mathrm{s}^{-1}$. Using the expression given before for correcting the shear effect would yield a deep current $\mathbf{u}_{\text {deep }}^{9}=(1.88$, $-1.94) \mathrm{cm} \mathrm{s}^{-1}$ since the error is $(0.74,0.12) \mathrm{cm} \mathrm{s}^{-1}$. However, it is clear in Fig. 29 that the surface velocity at AET is westward, whereas the ANDRO $\mathbf{U}_{\text {surf,first }}^{9}$ (estimated over the first $6 \mathrm{~h}$ ) is strongly eastward. This error estimate should be considered as an absolute value, only to provide an order of magnitude, as in YoMaYa'05 $\left(\varepsilon_{\text {Udeep }}^{n}=\left|\hat{U}_{\text {deep }}^{n}-u_{\text {deep }}^{n}\right|, \varepsilon_{\text {Vdeep }}^{n}=\right.$ $\left.\left|\hat{V}_{\text {deep }}^{n}-v_{\text {deep }}^{n}\right|\right)$.

We can, however, estimate more neatly the shear correction, since the extrapolation performed using a uniform current plus a circular inertial motion also gives the instantaneous velocities for descent start location and time at the end of cycle 8 and for ascent end location and time during cycle 9. They are $\mathbf{U}_{\text {surf }}^{8}(\mathrm{DST})=(31.0,-2.6)$ $\mathrm{cm} \mathrm{s}^{-1}$ and $\mathbf{U}_{\text {surf }}^{9}($ AET $)=(-92.5,-25.4) \mathrm{cm} \mathrm{s}^{-1}$. With these values, one obtains what is likely to be a more realistic deep current $\widehat{\mathbf{u}}_{\text {deep }}^{9}=(3.86,-2.51) \mathrm{cm} \mathrm{s}^{-1}$. One can still refine this estimate if we assume that the uniform current shear concerns only the upper $1000 \mathrm{~m}$ (one needs to replace the $1 / 2$ factor by a $1 / 3$ factor in the expression giving the shear correction), giving instead $(3.72,-2.56) \mathrm{cm} \mathrm{s}^{-1}$.

\section{APPENDIX B}

\section{Transmission Start Time Estimation for APEX}

Data messages are transmitted as follows. The $M$ messages are transmitted sequentially (from 1 to $M$ ) and repeatedly until the end of the UP TIME period. Thus, $B$ blocks of $M$ messages are transmitted, but the last block is not necessarily complete. 
TABLE D4. Meaning of "date flag" codes (column 5).

\begin{aligned} \hline \hline Date flag code & \multicolumn{1}{c}{ Meaning } \\ \hline 1 & Dated by a satellite \\ 2 & Dated by the float \\ 3 & Computed-estimated by a program \\ 4 & Manually modified \\ 5 & Coming from a human operator \\ 6 & Modified by a program \\ 7 & \\ 8 & \\ 9 & Default value \\ 99 & Corrected from clock drift \\ +10 & \end{aligned}

All data messages are numbered. Moreover, message 1 gives the block number. Since all messages received by the ARGOS satellite are dated, we get the times of transmission of the messages received and their numbers. For messages 1, we get also the block numbers to which they belong.

This allows the estimation of TSD as follows. If one has a message 1 , we can calculate the number of transmitted messages since TSD as (block\# -1$) \times M$ and thus the time elapsed since then (given the Argos PTT period, RepRate). This is the method proposed by Teledyne Webb Research. In summary, this method needs the following:

- receipt of at least one message 1 (otherwise, the determination is not possible),

- knowledge of the RepRate period of the Argos PTT (given in its user manual). and

- knowledge of the total number $M$ of messages that are actually transmitted.

This latter parameter, however, may be difficult to obtain. It cannot be obtained for sure from the received data, because it is possible that at least one of the $M$ different messages transmitted is never received (this happens). It could be determined with good knowledge of the way the messages are constituted, since the variable part of the message, that is the size devoted to the profile, is also given in messages 1 (but we still need to receive a message 1 and to know RepRate).

To avoid these difficulties, a second method (see Fig. B1) for estimating TSD is preferred.

The reception of two message 1s, belonging to two different blocks, allows estimating the transmission period of a block and thus the TSD. This method does not require knowledge of the RepRate nor the number $M$ of transmitted messages within a block. But this method does need the reception of at least two message 1s belonging to two different blocks.
TABLE D5. Meaning of “position flag” codes (column 10).

\begin{tabular}{cl}
\hline \hline Position flag code & \multicolumn{1}{c}{ Meaning } \\
\hline 0 & Float launch position \\
1 & Given by Argos or GPS satellite system \\
2 & Created (by extrapolation) \\
3 & Created (by interpolation) \\
4 & \\
5 & \\
6 & \\
7 & \\
8 & \\
9 & Default value \\
99 & Linear interpolation \\
+10 & Linear + inertial interpolation \\
+20 &
\end{tabular}

\section{APPENDIX C}

\section{Nakamura et al. Test}

We consider all the successive Argos surface positions recovered with location classes 1,2 , or 3 only. Then, we identify the surface trajectory segments (between two successive positions) where the speeds (along the segments) are greater than $3 \mathrm{~m} \mathrm{~s}^{-1}$ and whose lengths are greater than $\sqrt{\varepsilon_{A}^{2}+\varepsilon_{B}^{2}}$, where $A$ and $B$ are the two successive positions of a segment and $\varepsilon_{A}$ and $\varepsilon_{B}$ are the Argos circular error radii $(150,350$, and $1000 \mathrm{~m}$ for Argos classes 3, 2, and 1, respectively).

If the Argo classes at $A$ and $B$ are different, the less accurate position is flagged as bad and is not considered in ANDRO generation.

Figure $\mathrm{C} 1$ shows an example with six Argos fixes on 6 July 2007 at 0916:37, 1053:49, 1056:50, 1257:29, 1423:39, and 1435:55 UTC. The second segment must be flagged because its length is greater than the root-square sum of

TABLE D6. Meaning of "location class" codes (column 11).

\begin{tabular}{|c|c|}
\hline $\begin{array}{l}\text { Location class } \\
\text { code }\end{array}$ & Meaning \\
\hline '0’ & Argos location class $0($ precision $\geq 1000 \mathrm{~m})$ \\
\hline ' 1 ' & $\begin{array}{l}\text { Argos location class } 1(350 \mathrm{~m} \leq \text { precision }< \\
1000 \mathrm{~m})\end{array}$ \\
\hline ' 2 ' & $\begin{array}{l}\text { Argos location class } 2(150 \mathrm{~m} \leq \text { precision }< \\
350 \mathrm{~m})\end{array}$ \\
\hline ' 3 ' & Argos location class 3 (precision $<150 \mathrm{~m}$ ) \\
\hline 'A' & $\begin{array}{l}\text { Argos location class A (computed from three } \\
\text { Argos messages) }\end{array}$ \\
\hline 'B' & $\begin{array}{l}\text { Argos location class B (computed from two Argos } \\
\text { messages) }\end{array}$ \\
\hline ' $\mathrm{Z}$ ' & Argos location class Z (invalid) \\
\hline 'G' & GPS location \\
\hline '9’ & Default value \\
\hline
\end{tabular}


TABLE D7. Meaning of "measurement flag" codes (columns 14, 16, and 18).

\begin{aligned} & \hline \hline Measurement flag code \multicolumn{1}{c}{ Meaning } \\ & \hline 0 No QC performed \\ & 1 Good data \\ & 2 Probably good data \\ & 3 Bad data that are potentially correctable \\ & 4 Bad data \\ & 5 Value changed \\ & 6 \\ & 7 \\ & 8 Interpolated value \\ & 9 Missing value \\ & 999 Default value \\ &+10 Manually modified \\ &+20 Modified by a program \\ &+40 Corrected of the offset \\ &+80 Not correctable of the offset \\ & \hline\end{aligned}

the errors and the induced velocity is greater than $10 \mathrm{~m} \mathrm{~s}^{-1}$.

If the Argo classes at $A$ and $B$ are the same, and there is one good position before and one good position after $A$ and $B$ (i.e., there are four positions for the check; see Fig. $\mathrm{C} 2$ ), then the position that gives the higher mean speed along the trajectory from the previous good position to the latter good position is flagged as bad (and not considered in ANDRO generation).

If the Argo classes at $A$ and $B$ are the same, but there is only one good position either before or after $A$ and $B$ (i.e., there are three positions for the check), then the position that gives the higher speed along the segment either from the previous good position or to the later good position is flagged as bad (and not considered in ANDRO generation). In case there are no good positions around $A$ and $B$ (i.e., there are only the two positions $A$ and $B$ for the check), then both $A$ and $B$ are flagged as bad and are not considered in ANDRO generation.

The Nakamura et al. (2008) test has been used successfully on all the Argos surface positions; we have never recorded any mistakes.

TABLE D8. Meaning of “grounded flag” codes (column 19).

\begin{tabular}{cl}
\hline \hline Grounded flag code & \multicolumn{1}{c}{ Meaning } \\
\hline UF & U: user digit (finally used digit) \\
& F: float digit (information transmitted \\
& by the float) \\
& Unknown information \\
0 & Not grounded \\
1 & Grounded \\
2 & Default value \\
\hline
\end{tabular}

TABLE D9. Meaning of "data origin or state" codes (column 20).

\begin{tabular}{|c|c|}
\hline $\begin{array}{l}\text { Data origin or } \\
\text { state code }\end{array}$ & Meaning \\
\hline 1 & $\begin{array}{l}\text { From PROF or TRAJ NetCDF file } \\
\quad \text { (real-time data) }\end{array}$ \\
\hline 2 & From TECH NetCDF file \\
\hline 3 & Directly from Argos raw data \\
\hline 4 & From decoded Argos raw data \\
\hline 5 & $\begin{array}{l}\text { From DAC-decoded ASCII files (.profile } \\
\text { from Optimare or .TXT from Coriolis) }\end{array}$ \\
\hline 6 & From META NetCDF file \\
\hline 7 & From DEP file \\
\hline 8 & \\
\hline 9 & \\
\hline 99 & Default value \\
\hline+10 & Manually modified \\
\hline+20 & Modified by a program \\
\hline+40 & Corrected from cycle number errors \\
\hline
\end{tabular}

\section{APPENDIX D}

\section{The DEP Format}

The corrected dataset used to generate the ANDRO atlas is composed of ( 22 column) ASCII files called DEP files (for "deplacement"). There is one file per float in the DEP dataset. The DEP format is described in Tables D1-D9.

\section{REFERENCES}

Davis, R. E., 2005: Intermediate-depth circulation of the Indian and south Pacific Oceans measured by autonomous floats. J. Phys. Oceanogr., 35, 683-707.

, and W. Zenk, 2001: Subsurface Lagrangian observations during the 1990s. Ocean Circulation and Cimate, G. Siedler, J. Church, and J. Gould, Eds., International Geophysics Series, Vol. 77, Academic Press, 123-139.

— D. C. Webb, L. A. Regier, and J. Dufour, 1992: The autonomous Lagrangian circulation explorer (ALACE). J. Atmos. Oceanic Technol., 9, 264-285.

Lebedev, K. V., H. Yoshinari, N. A. Maximenko, and P. W. Hacker, 2007: YoMaHa'07-Velocity data assessed from trajectories of Argo floats at parking level and at the sea surface. IPRC Tech. Note 4 (2), 16 pp.

Nakamura, T., N. Ogita, and T. Kobayashi, 2008: Quality control method of Argo float position data. JAMSTEC Rep. Res. Dev., 7, 11-18.

Ollitrault, M., and J. P. Rannou, 2010: ANDRO: An Argo-based deep displacement atlas. Joint Coriolis-Mercator Ocean Quarterly Newsletter, No. 37, Mercator Ocean, Toulouse, France, 29-36. , G. Loaëc, and C. Dumortier, 1994: MARVOR: A multi-cycle RAFOS float. Sea Technol., 35 (2), 39-44.

M. Lankhorst, D. Fratantoni, P. Richardson, and W. Zenk, 2006: Zonal intermediate currents in the equatorial Atlantic Ocean. Geophys. Res. Lett., 33, L05605, doi:10.1029/ 2005 GL025368. 
Park, J. J., K. Kim, and W. R. Crawford, 2004: Inertial currents estimated from surface trajectories of Argo floats. Geophys. Res. Lett., 31, L13307, doi:10.1029/2004GL020191.

, B. A. King, and S. C. Riser, 2005: An advanced method to estimate deep currents from profiling floats. J. Atmos. Oceanic Technol., 22, 1294-1304.

Rossby, T., and D. Webb, 1970: Observing abyssal motion by tracking Swallow floats in the SOFAR channel. Deep-Sea Res., 17, 359-365. D. Dorson, and J. Fontaine, 1986: The RAFOS system. J. Atmos. Oceanic Technol., 3, 672-679.
Swallow, J. C., 1955: A neutral-buoyancy float for measuring deep currents. Deep-Sea Res., 3, 74-81.

Wunsch, C., 2008: The past and future Ocean circulation from a contemporary perspective. Ocean Circulation: Mechanisms and Impacts, Geophys. Monogr., Vol. 173, Amer. Geophys. Union, 53-74.

Yoshinari, H., N. A. Maximenko, and P. W. Hacker, 2006: YoMaHa'05-Velocity data assessed from trajectories of Argo floats at parking level and at the sea surface. IPRC Tech. Note 4, 16 pp. 